\title{
Multiperiod Dynamic Pricing and Inventory Control Decisions for an Omnichannel BOPS Retailer with Reference Price Effects
}

\author{
Yuan Li iD \\ College of Mathematics and Physics, Inner Mongolia University for the Nationalities, Tongliao 028000, \\ The Inner Mongolia Autonomous Region, China \\ Correspondence should be addressed to Yuan Li; imunliyuan@163.com
}

Received 26 July 2020; Revised 9 October 2020; Accepted 21 January 2021; Published 5 February 2021

Academic Editor: Josefa Mula

Copyright (c) 2021 Yuan Li. This is an open access article distributed under the Creative Commons Attribution License, which permits unrestricted use, distribution, and reproduction in any medium, provided the original work is properly cited.

This paper utilizes the consumers' reference price in prospect theory to analyze an omnichannel retailer's multiperiod pricing and inventory management problem in which consumers can cancel their orders before payment and return the products after payment if the products do not meet their expectation. The omnichannel retailer's optimal equilibrium pricing and ending inventory level are derived under reference price effects by maximizing the discounted total profit over the infinite planning horizon, where the optimal decisions we discussed under two scenarios: loss neutrality and loss aversion. The analysis shows that the convergence of the pricing and ending inventory level toward their equilibrium is from above or below, depending on the relative location of the initial reference price with respect to the unique equilibrium price. Moreover, a set of sensitivity analyses is discussed to characterize the impacts of system parameters on the optimal decisions. This research fills the gap of behavioral operation in the field of omnichannel joint pricing and inventory management.

\section{Introduction}

With the vigorous development of mobile Internet technology, great changes have taken place in the communication between retailers and consumers. In order to improve the probability of successful marketing and increase market share, retailers have emerged a series of new retail modes, such as online, mobile, e-mail, and QQ, and a new retail model that opens up various channels, "omnichannel retail" came into being. For example, facing the competition from JD.com, both Suning and Gome, the two largest traditional physical home appliance retailers in China, launched their online businesses in 2009. Additionally, the world-famous e-commerce retailers, such as Amazon, Google, and eBay, have also built their techenabled physical stores. Omnichannel retail focuses on "a truly integrated approach across the whole retail operation that delivers a seamless response to the consumer experience through all available shopping channels" (see, for example, $[1,2]$ ). Through channel integration, not only can the trust and satisfaction of consumers be improved but also the competitive advantage and channel synergy of retailers can be improved, so as to better match the channels and consumers. Data show that the global e-commerce sales reached $\$ 1.86$ trillion in 2016 and reached $\$ 3.88$ trillion in 2018, with a growth rate of over $10 \%$ [3]. With the strong support for e-commerce, the innovative business model based on Internet plus has developed rapidly in China, domestic retail giants such as Suning, JD, and Taobao have emerged, and they are constantly exploring new omnichannel business models. At present, pay-and-buy-online-pick-up-in-store (BOPS) is a retail mode that is widely adopted by omnichannel retail. Taking Suning as an example, consumers can enjoy store pick up, store appraisal, and store return and exchange services at any physical store across the country after placing an order on the Suning cloud platform [4]. In addition, BOPS can also bring potential additional transactions for offline stores, which is called cross-selling profit [5]. A recent United Parcel Service (UPS) study shows that $45 \%$ of consumers will have new purchase when they pick up goods offline [6]. The implementation of the BOPS gives 
full play to the offline advantages of traditional retailers and enhances retailers' competitive advantages via offline professional services, convenience, and experience advantages.

As an important practice of omnichannel retail, BOPS has been adopted by many retailers, but it also faces many technical challenges. These challenges mainly come from two levels: retailers and consumers. First of all, at the retailer level, omnichannel retail online and offline inventory sharing, in order to ensure the availability of goods purchased by consumers at any time, it is particularly important to formulate a reasonable inventory and a balanced price strategy, which will help improve consumers' loyalty and the reputation of retailers. Secondly, at the consumer level, it is mainly manifested in the purchase behavior of consumers. Consumers' purchase decision will be affected by the reference price. Behavioral science pointed out that consumers will remember the past price information of a product in their mind when they repeatedly purchase a product, thereby establishing the concept of "fair price," which is called reference price [7]. When a new purchase decision is made for the same product, consumers will take the reference price as the benchmark of the current selling price of the product. If the current selling price is lower (higher) than the reference price, they will think that they have "earned" ("lost") and are, therefore, more likely (unwilling) to buy. This phenomenon is called reference price effects. Research shows that the joint pricing and inventory strategies based on the reference price effects can greatly increase the profits of retailers [8]; thirdly, the common phenomenon of consumer return under the BOPS mode will also affect the decision making of retailers [5]. Thus, the following technical problems will arise: (1) How will the BOPS mode affect an omnichannel retailer' market demand and profitability? (2) What pricing and inventory decisions should the retailer make to realize the product price advantage, save inventory cost, and improve profit? These are the practical problems that need to be solved urgently when the retailer implements the BOPS mode. The solution of these problems meets the current development needs and has important practical significance.

In order to solve the abovementioned problems, this paper studies the pricing and inventory strategies of an omnichannel retailer with BOPS mode based on the influence of consumers' reference price. By analyzing the mechanism of the influence of consumer reference price on the pricing and inventory of the omnichannel retailer, it provides theoretical suggestions for omnichannel retailers to implement the pricing and inventory management of the BOPS mode, whereas recent research on joint pricing and inventory decisions of omnichannel retailers mainly focused on single ordering cycle and ignored the consumers' reference price effects (see, for example, $[5,9]$ ). Besides, previous literature on multiperiod coordination pricing and inventory control problem with reference price effects mainly focused on the single-channel supply chain, and little attention has been paid to the omnichannel field (see, for example, $[8,10,11])$. This paper studies the multiperiod joint pricing and inventory strategies of omnichannel retailers considering the impact of consumers' reference price and tries to fill the gap in the decision making of multiperiod joint pricing and inventory in an omnichannel environment.

The rest of the paper is organized as follows. Section 2 reviews the related literature. Section 3 presents a theoretical model to formulate the omnichannel under reference price effects. Section 4 investigates several structural properties of the optimal strategies. Numerical results of sensitivity analysis are represented in Section 5. Some managerial insights are provided in Section 6. Section 7 concludes our paper. All the proofs are presented in Appendix.

\section{Literature Review}

This paper is related to two streams of literature: one delves into omnichannel retail operations, while the other discusses the multiperiod pricing-inventory model with reference price effects. We review the related areas below.

Studies on omnichannel retailing are emerging, most of which are exploratory. At present, the omnichannel BOPS operation management has attracted extensive attention from the academic community. According to Retail Systems Research (RSR), as of June 2013, 64\% of the retailers provided consumers with the option to BOPS [12], and they benefit from allowing consumers to pick up their online orders in store. According to a recent UPS study, among those who have used an in-store pick up option, $45 \%$ of them have made a new purchase when picking up the product in store (UPS, 2015). Such an additional profit is called the cross-selling benefit $[6,13]$. Actually, such cross selling can generate a substantial amount of store sales: it is estimated that, on average, when a consumer comes to the store intending to buy $\$ 100$ worth of merchandise, he/she leaves with \$120 to \$125 worth of merchandise [14]. Some recent works explore the pricing strategies of the omnichannel retailer. Zhang et al. [15] analyze the pricing problem when retailers who implement the BOPS model compete with those who only implement network channel operation. Harsha et al. [16] consider the pricing strategy of online and offline inventory sharing. However, there are few studies that consider coordination of pricing and inventory decisions. Fan et al. [17] discuss the problem of pricing and inventory decision making where an online retailer and an offline retailer cooperate to implement the BOPS mode. Moreover, it is worth mentioning that the BOPS mode requires consumers to pay at the moment of ordering online, and they know the exact value of the product only after receiving/picking it, which may cause many product returns [18]. Thus, $\mathrm{Liu}$ and $\mathrm{Xu}$ [9] investigate an omnichannel BOPS retailer's pricing and ordering model considering online returns. Zhang et al. [5] consider the omnichannel BOPS mode that allows both online and offline consumers to return and cancel orders. Their mode allows a consumer who places an order online to choose to (i) pay online and wait for the package delivered via an express company or (ii) visit the physical stores to touch and feel the product before payment and then buy and pick up it. The BOPS mode in our paper follows the assumption of [5], i.e., a consumer who places an order online can choose to (i) or (ii) according to personal preference. The main differences between our's and [5] are as follows: First, we consider the 
multiperiod joint pricing and inventory model, while they consider the single-period setting; second, we consider the consumers' behavior, i.e., reference price effects, which is ignored in their study. The abovementioned studies have a common characteristic that none of them consider the consumers' behavior. In reality, consumers' behaviour has a significant impact on retailers' operation and marketing strategies. Thus, it is necessary to consider the consumers' behaviour when making the joint pricing and inventory strategies.

The second stream of related research is on the periodic review joint pricing and inventory model with reference price effects. This line of research started with Gimpl-Heersink [19], who proves the optimality of the base-stock-list-price for the single-period and two-period models when the customers are loss neutral. However, the optimality of the base-stock-list-price is stricter for the multiperiod setting. Urban [20] analyzes a single-period joint pricing and inventory model with symmetric and asymmetric reference price effects and shows that the consideration of the reference price has a substantial impact on the firm's profitability. Taudes and Rudloff [21] provide an application of the two-period model from the work of GimplHeersink [19] to electronic commodities. Zhang [22] uses a class of transformation techniques to prove the optimality of the basestock-list-price policy, even if the single-period profit function is nonconcave. Güler et al. [10] extend the model of [19] to the concave demand function, and they address the nonconcavity of the revenue function by combining the transformation technique proposed by Zhang [22] and the inverse demand function. The optimality of the state-dependent order-up-to strategy is proved for the transformed concave revenue function model. Güler et al. [11] use the safety stock as a decision variable to characterize the steady state solution to the problem when the planning horizon is infinite. Chen et al. [8] introduce a new concave transform technique to ensure that the profit function is concave by using the preservation property of supermodularity in parameter optimization problems with the nonlattice structure proposed in [23] and then prove the optimality of the basestock-list-price strategy. Li and Teng [24] investigate the multiperiod pricing and inventory decisions for perishable goods when demand depends on selling price, reference price, product freshness, and displayed stocks. For other related works in this stream of research, interested readers may refer to the review by Ren and Huang [25]. In summary, the abovementioned studies have shown that reference price effects have important effects on retailer decision making, but the retailer's joint pricing and inventory strategies considering reference price effects are still inadequate in an omnichannel retail environment. This gives a reason for us to investigate this gap.

\section{Model Description}

3.1. Modeling the Omnichannel under Reference Price Effects. We consider a retailer ("he"), initially an online retailer, who previously operated a single online channel that only allowed consumers to shop online directly. Currently, he has added a physical store and implemented the omnichannel strategy, which allows consumers to place orders online without paying immediately. With this allowance, a consumer ("she") who places an order online can choose to (i) pay online and wait for the package delivered or (ii) visit the physical stores to touch and feel the product before payment and then buy and pick up it (i.e., choose "BOPS"). The buying procedure of a consumer who orders online is depicted in Figure 1, where $1-\sigma$ and $\sigma$ are the fractions of consumers who place orders online by choosing to (i) and (ii), respectively.

As shown in Figure 1, after placing an order online, if a consumer chooses to (i), she knows the exact value of the product only after receiving it. If the actual value does not meet her expectation, she can return the product with a full refund [26], but she needs to pay the return shipping fee for each unit of the product [27]. Suppose the forward shipping fee is paid by the retailer while the return shipping fee is paid by the consumer and the express company charges the same shipping fee $m$ for both of them. If an online consumer chooses to (ii), she needs to pay a travelling cost $t(t>0)$ to visit the store and then decide whether to keep the product or cancel the order in store. The cancellation of the orders does not pay anything. Moreover, assume that there is an additional cross-selling profit $l$ from every consumer visiting the store [6].

The omnichannel retailer orders and sells a single item over an infinite planning horizon. Suppose the inventory periods are identical with equal length $T$ and the shortages are not allowed. The inventory is shared across channels [28], and the replenishment rate is complete and instantaneous. Let $I_{i}(t)$ be the inventory level at time $t$ in the $i$ th period. Demand rate is proportional to $\left[I_{i}(t)\right]^{a}$, where $0 \leq a<1$ implies the diminishing marginal effect of inventory level on demand. The retailer charges the same price $p_{i}\left(p \leq p_{i} \leq \bar{p}\right)$ in the $i$ th period over the physical and online channels. The cost of purchase is $c$ per unit, and let $h$ be the holding cost per unit and $s$ be the salvage value per unit satisfying $p_{i}>c>s$. Let $v_{i}$ be the consumer's valuation for the product in the $i$ th period which is random and follows the cdf $G(\cdot)$ (also the pdf $g(\cdot)$ ). Without loss of generality, we assume that $v_{i}>c$. The reference price depends on past prices and the current price. A commonly used model for the evolution of the reference price is the exponential smoothing model (see, for example, $[8,10,11])$ :

$$
\begin{array}{r}
r_{i}=\alpha r_{i-1}+(1-\alpha) p_{i-1}=\alpha^{i-1} r_{1}+(1-\alpha) \sum_{j=1}^{i-1} \alpha^{i-1-j} p_{j}, \\
i=2,3,4, \ldots,
\end{array}
$$

where the initial reference price $r_{1}$ is known and $\alpha(0 \leq \alpha<1)$ is the memory factor. The larger the $\alpha$, the longer the memory. If $\alpha$ is high, then consumers have a long memory and the past price effect is larger. If $\alpha$ is small, then the current price has a greater effect than the past on the reference price. The initial reference price is given by $r_{1} \in[p, \bar{p}]$, and then, all $r_{t}$ belong to the interval.

The demand rate at time $t$ in the $i$ th period, denoted by $X\left(p_{i}, r_{i}, t\right)$, is a multiplicative form of the selling price 


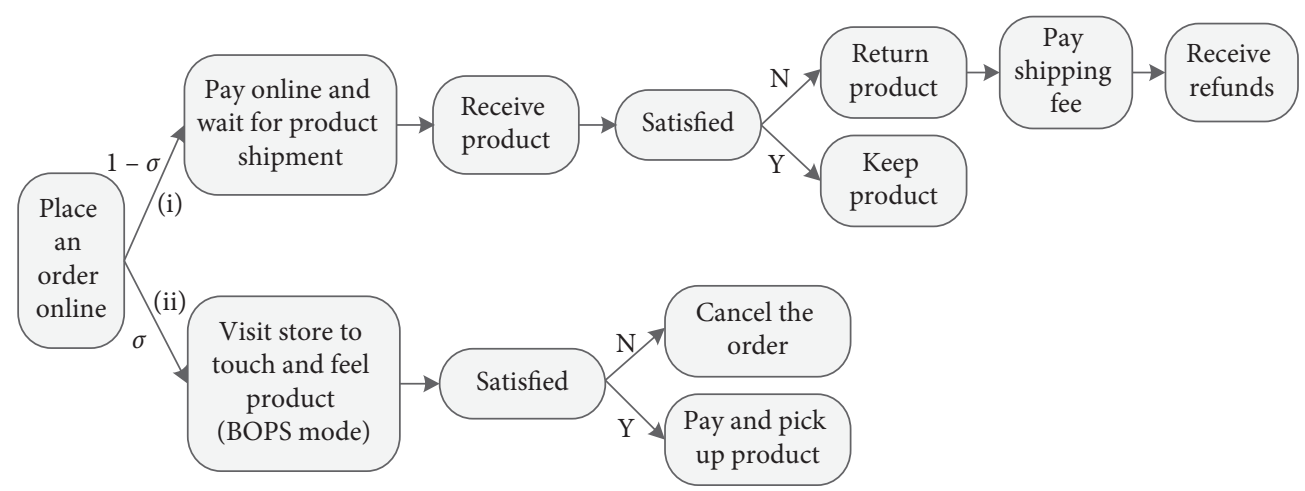

FIGURE 1: Buying procedure of a consumer who orders online under the omnichannel environment.

$p_{i}$, reference price $r_{i}$, and inventory level $I_{i}(t)$, which is given by

$$
\begin{aligned}
X\left(p_{i}, r_{i}, t\right)= & \left\{\beta_{0}-\beta_{1} p_{i}-\lambda \times \max \left\{p_{i}-r_{i}, 0\right\}\right. \\
& \left.-\gamma \times \min \left\{p_{i}-r_{i}, 0\right\}\right\}\left[I_{i}(t)\right]^{a},
\end{aligned}
$$

where the nonnegative parameters $\lambda$ and $\gamma$ measure the sensitivities of demand associated with the perceived losses and gains, respectively. Demand is classified as loss averse, loss neutral, or loss seeking, depending on whether $\lambda>\gamma, \lambda=\gamma$ or $\lambda<\gamma$. Let $k(0<k<1)$ be the fraction of the demand served under the single online channel, i.e., the demand was $k X\left(p_{i}, r_{i}, t\right)$ at time $t$ in the $i$ th period when the retailer used to operate a single offline channel. However, the omnichannel strategy will lead to an incremental demand $(1-k) X\left(p_{i}, r_{i}, t\right)$ for the retailer from both the online and offline channels at time $t$ in the $i$ th period [17]. Let $\rho$ and $1-\rho$ be the fractions of the incremental demand coming from the online and the offline market, respectively. Then, at time $t$ in the $i$ th period, the online channel demand is increased from $k X\left(p_{i}, r_{i}, t\right)$ to $[k+\rho(1-k)] X\left(p_{i}, r_{i}, t\right)$, and offline channel demand is increased from 0 to $(1-\rho)(1-k) X\left(p_{i}, r_{i}, t\right)$.

During the $i$ th period, the depletion of the inventory due to the effect of demand, $I_{i}(t)$ can be expressed by the following differential equation:

$$
\begin{aligned}
I_{i}^{\prime}(t)= & -X\left(p_{i}, r_{i}, t\right)-\left\{\beta_{0}-\beta_{1} p_{i}-\lambda \times \max \left\{p_{i}-r_{i}, 0\right\}\right. \\
& \left.-\gamma \times \min \left\{p_{i}-r_{i}, 0\right\}\right\}\left[I_{i}(t)\right]^{a}
\end{aligned}
$$

with the boundary condition $I_{i}(T)=E_{i}$, where $E_{i}$ is the ending inventory level in the $i$ th period. Without loss of generality, we assume that $E_{i}>0$. Solving differential equation (3) gives

$$
I_{i}(t)=\left\{E_{i}^{1-a}+(1-a)(T-t)\left[\beta_{0}-\beta_{1} p_{i}-\lambda \times \max \left\{p_{i}-r_{i}, 0\right\}-\gamma \times \min \left\{p_{i}-r_{i}, 0\right\}\right]\right\}^{(1 / 1-a)},
$$

$0 \leq t \leq T$. The time-weighted inventory during the $i$ th period is as follows:

$$
\int_{0}^{T} I_{i}(t) \mathrm{d} t=\int_{0}^{T}\left\{E_{i}^{1-a}+(1-a)(T-t)\left[\beta_{0}-\beta_{1} p_{i}-\lambda \times \max \left\{p_{i}-r_{i}, 0\right\}-\gamma \times \min \left\{p_{i}-r_{i}, 0\right\}\right]\right\}^{(1 / 1-a)} .
$$

In an omnichannel retail environment, the exact inventory information is available to the consumers when they place orders online, and they will not order the products for those out of stock. Hence, a consumer who places an order online does not suffer a utility loss from the stock-out risk. In the following sections, we start with the case of loss neutral demand (i.e., $\lambda=\gamma$ ) and then extend our analysis to the case of loss averse demand. Thus, we give the utility of a consumer at different trading times for both online and offline payment under the omnichannel strategy with the case of loss neutral demand in Table 1.
As can be seen from Table 1, the consumer utility of buy online directly and BOPS is $\max \left\{v_{i}-p_{i}+\lambda\left(r_{i}-p_{i}\right),-m\right\}$ and $\max \left\{v_{i}-p_{i}+\lambda\left(r_{i}-p_{i}\right)-t,-t\right\}$, respectively. According to the principle of utility maximization, if a consumer chooses the buy online directly channel, then the probabilities that he/she keeps and returns the product are $\bar{G}\left(p_{i}-m-\lambda\left(r_{i}-p_{i}\right)\right)$ and $G\left(p_{i}-m-\lambda\left(r_{i}-p_{i}\right)\right)$, respectively. If a consumer chooses the BOPS, the probabilities that he/she chooses to buy or not buy the product are $\bar{G}\left(p_{i}-\gamma\left(r_{i}-p_{i}\right)\right)$ and $G\left(p_{i}-\gamma\left(r_{i}-p_{i}\right)\right)$, respectively. Similarly, the probabilities that an offline consumer chooses 
TABLe 1: Consumer utility under two different channels when demand is loss neutral.

\begin{tabular}{|c|c|c|c|c|}
\hline \multirow[b]{2}{*}{ Demand source } & \multirow[b]{2}{*}{ Purchase channels } & At the time of placing the order & \multicolumn{2}{|c|}{ At the time of receiving the product } \\
\hline & & Place order & Keep (buy) product & $\begin{array}{l}\text { Return product/cancel } \\
\text { order/leave store }\end{array}$ \\
\hline Online consumers & Buy online directly & $-p_{i}$ & $v_{i}-p_{i}+\lambda\left(r_{i}-p_{i}\right)$ & $-m$ \\
\hline Offline consumers & Buy offline directly & 0 & $\begin{array}{l}v_{i}-p_{i}+\lambda\left(r_{i}-p_{i}\right)-t \\
v_{i}-p_{i}+\lambda\left(r_{i}-p_{i}\right)-t\end{array}$ & $\begin{array}{l}-t \\
-t\end{array}$ \\
\hline
\end{tabular}

to buy or not buy are $\bar{G}\left(p_{i}-\gamma\left(r_{i}-p_{i}\right)\right)$ and $G\left(p_{i}-\gamma\left(r_{i}-p_{i}\right)\right)$, respectively.
Based on the abovementioned analysis, the omnichannel retailer's total profit during the $\mathrm{i}^{\text {th }}$ period can be written as

$$
\begin{aligned}
\pi\left(p_{i}, r_{i}, E_{i}\right), \\
=\left[p K_{1}(1-\sigma) \bar{G}\left(p_{i}-m-\lambda\left(r_{i}-p_{i}\right)\right)+s K_{1}(1-\sigma) G\left(p_{i}-m-\lambda\left(r_{i}-p_{i}\right)\right)-m K_{1}(1-\sigma)\right. \\
\left.\quad+p K_{1} \sigma \bar{G}\left(p_{i}-\lambda\left(r_{i}-p_{i}\right)\right)+s K_{1} \sigma G\left(p_{i}-\lambda\left(r_{i}-p_{i}\right)\right)+l K_{1} \sigma+p K_{2} \bar{G}\left(p_{i}-\lambda\left(r_{i}-p_{i}\right)\right)+s K_{2} G\left(p_{i}-\lambda\left(r_{i}-p_{i}\right)\right)+l K_{2}\right] \\
\quad \cdot\left[I_{i}(0)-E_{i}\right]-c I_{i}(0)+s E_{i}-h \int_{0}^{T} I_{i}(t) \mathrm{d} t \\
=\left[\lambda_{1} A\left(p_{i}, r_{i}\right)+\lambda_{2} B\left(p_{i}, r_{i}\right)+s\right] \cdot\left[I_{i}(0)-E_{i}\right]-c I_{i}(0)+s E_{i}-h \int_{0}^{T} I_{i}(t) \mathrm{d} t,
\end{aligned}
$$

where $\quad K_{1}=\rho(1-k)+k, \quad K_{2}=(1-\rho)(1-k), \quad$ and $K_{1}+K_{2}=1 . \quad \lambda_{1}=(1-\sigma) K_{1}, \quad \lambda_{2}=\sigma K_{1}+K_{2}, \quad$ and $\lambda_{1}+\lambda_{2}=1$.
Due to the complexity of $h \int_{0}^{T} I_{i}(t) \mathrm{d} t$, following [24, 29], we use the average inventory holding cost $\left(h T\left[I_{i}(0)+E_{i}\right] / 2\right)$ to estimate the holding cost during the period. Then, the total profit (6) becomes

$$
\begin{aligned}
\pi\left(p_{i}, r_{i}, E_{i}\right)= & {\left[\lambda_{1} A\left(p_{i}, r_{i}\right)+\lambda_{2} B\left(p_{i}, r_{i}\right)-(c-s)\right] \cdot\left[\varphi^{\lambda}\left(p_{i}, r_{i}, E_{i}\right)\right]^{(1 / 1-a)} } \\
& -\left[\lambda_{1} A\left(p_{i}, r_{i}\right)+\lambda_{2} B\left(p_{i}, r_{i}\right)\right] E_{i}-\frac{h T}{2}\left\{\left[\varphi^{\lambda}\left(p_{i}, r_{i}, E_{i}\right)\right]^{(1 / 1-a)}+E_{i}\right\} \\
= & {\left[\lambda_{1} A\left(p_{i}, r_{i}\right)+\lambda_{2} B\left(p_{i}, r_{i}\right)-(c-s)-\frac{h T}{2}\right] \cdot\left[\varphi^{\lambda}\left(p_{i}, r_{i}, E_{i}\right)\right]^{(1 / 1-a)} } \\
& -\left[\lambda_{1} A\left(p_{i}, r_{i}\right)+\lambda_{2} B\left(p_{i}, r_{i}\right)+\frac{h T}{2}\right] E_{i},
\end{aligned}
$$

where $A\left(p_{i}, r_{i}\right), B\left(p_{i}, r_{i}\right)$ are defined in Section 3.2 and

$$
\phi^{\lambda}\left(p_{i}, r_{i}, E_{i}\right)=E_{i}^{1-a}+(1-a) T\left[\beta_{0}-\beta_{1} p_{i}-\lambda\left(p_{i}-r_{i}\right)\right] .
$$

We notice from (7) that $\lambda_{1} A\left(p_{i}, r_{i}\right)+\lambda_{2} B\left(p_{i}, r_{i}\right)-(c-$ $s)-(h T / 2)$ represents the gross unit profit, and we assume that $\quad \lambda_{1} A\left(p_{i}, r_{i}\right)+\lambda_{2} B\left(p_{i}, r_{i}\right)-(c-s)-(h T / 2)>0$ throughtout the paper. Moreover, 


$$
\begin{aligned}
\lim _{i} \longrightarrow \infty & \frac{\left[\lambda_{1} A\left(p_{i}, r_{i}\right)+\lambda_{2} B\left(p_{i}, r_{i}\right)-(c-s)-(h T / 2)\right] \cdot\left[\phi^{\lambda}\left(p_{i}, r_{i}, E_{i}\right)\right]^{(1 / 1-a)}}{E_{i}\left[\lambda_{1} A\left(p_{i}, r_{i}\right)+\lambda_{2} B\left(p_{i}, r_{i}\right)+(h T / 2)\right]} \\
& =\lim _{E_{i}} \frac{\left[\lambda_{1} A\left(p_{i}, r_{i}\right)+\lambda_{2} B\left(p_{i}, r_{i}\right)-(c-s)-(h T / 2)\right] \cdot\left\{E_{i}^{1-a}+(1-a) T\left[\beta_{0}-\beta_{1} p_{i}-\lambda\left(p_{i}-r_{i}\right)\right]\right\}^{(1 / 1-a)}}{E_{i}\left[\lambda_{1} A\left(p_{i}, r_{i}\right)+\lambda_{2} B\left(p_{i}, r_{i}\right)+(h T / 2)\right]} \\
& =\lim _{E_{i}} \frac{\left[\lambda_{1} A\left(p_{i}, r_{i}\right)+\lambda_{2} B\left(p_{i}, r_{i}\right)-(c-s)-(h T / 2)\right] \cdot\left\{1+\left((1-a) T\left[\beta_{0}-\beta_{1} p_{i}-\lambda\left(p_{i}-r_{i}\right)\right] / E_{i}^{1-a}\right)\right\}^{(1 / 1-a)}}{\left[\lambda_{1} A\left(p_{i}, r_{i}\right)+\lambda_{2} B\left(p_{i}, r_{i}\right)+(h T / 2)\right]} \\
& =\frac{\lambda_{1} A\left(p_{i}, r_{i}\right)+\lambda_{2} B\left(p_{i}, r_{i}\right)-(c-s)-(h T / 2)}{\lambda_{1} A\left(p_{i}, r_{i}\right)+\lambda_{2} B\left(p_{i}, r_{i}\right)+(h T / 2)}<1,
\end{aligned}
$$

which implies that $\lim _{E_{i}} \longrightarrow \infty \pi\left(p_{i}, r_{i}, E_{i}\right)=-\infty$. Therefore, $E_{i}$ is bounded, and we assume that $0 \leq E_{i}<\bar{E}<\infty$, where $\bar{E}$ is a large number.

Let $\Pi(\mathrm{P}, \mathrm{E})$ denote the omnichannel retailer's discounted total profit over the infinite planning horizon. Given the initial reference price $r_{1}$ and discount factor $z \in(0,1)$, the profit-maximizing problem is formulated as follows:

$$
\max _{(\mathrm{P}, \mathrm{E}) \in \Omega} \Pi(\mathrm{P}, \mathrm{E})=\sum_{i=1}^{\infty} z^{i-1} \pi\left(p_{i}, r_{i}, E_{i}\right),
$$

where $\mathrm{P}=\left\{p_{1}, p_{2}, p_{3}, \ldots\right\}, \mathrm{E}=\left\{E_{1}, E_{2}, E_{3}, \ldots\right\}$ and

$$
\Omega=\left\{(\mathrm{P}, \mathrm{E}): \underline{p} \leq p_{i} \leq \bar{p}_{i}^{2 *}\left(r_{i}\right)<\bar{p}, 0 \leq E_{i} \leq \bar{E}\right\} .
$$

It is worth mentioning that $p_{i} \leq \bar{p}_{i}^{2 *}\left(r_{i}\right)$ follows from Assumption 1 and Lemma 2 in Section 3.2, where $\bar{p}_{i}^{2 *}\left(r_{i}\right)$ is the solution of $L_{2}\left(p_{i}, r_{i}\right)=0$. In addition, we can obtain the following result, which indicates that the omnichannel retailer's discount total profit increases as the initial reference price increases.

Lemma 1. $\Pi(\mathrm{P}, \mathrm{E})$ is increasing in $r_{1}$.

3.2. Notations and Assumptions. The related parameters and variables used in this paper are summarized in Table 2; other notations will be defined as needed.

To facilitate the analysis, we define the following functions:

$$
\begin{aligned}
L_{1}\left(p_{i}, r_{i}\right) & =\bar{G}\left(p_{i}-m-\lambda\left(r_{i}-p_{i}\right)\right)-\left(p_{i}-s\right)(1+\lambda) g\left(p_{i}-m-\lambda\left(r_{i}-p_{i}\right)\right), \\
L_{3}\left(p_{i}, r_{i}\right) & =\bar{G}\left(p_{i}-\lambda\left(r_{i}-p_{i}\right)\right)-\left(p_{i}-s\right)(1+\lambda) g\left(p_{i}-\lambda\left(r_{i}-p_{i}\right)\right), \\
L_{2}\left(p_{i}, r_{i}\right) & =\lambda_{1} L_{1}\left(p_{i}, r_{i}\right)+\lambda_{2} L_{3}\left(p_{i}, r_{i}\right), \\
A\left(p_{i}, r_{i}\right) & =\left(p_{i}-s\right) \bar{G}\left(p_{i}-m-\lambda\left(r_{i}-p_{i}\right)\right)-m, \\
B\left(p_{i}, r_{i}\right) & =\left(p_{i}-s\right) \bar{G}\left(p_{i}-\lambda\left(r_{i}-p_{i}\right)\right)+l,
\end{aligned}
$$

where $\lambda_{1}=(1-\sigma)[1-(1-\rho) k]$ and $\lambda_{2}=\sigma[1-(1-\rho) k]+$ $(1-\rho) k$.

Furthermore, we need the following assumptions.
Assumption 1. Suppose $\lambda_{1} A\left(p_{i}, r_{i}\right)+\lambda_{2} B\left(p_{i}, r_{i}\right)-(c-s)-$ $(h T / 2)>0$ and $L_{2}\left(p_{i}, r_{i}\right)>0$.

Assumption 2. Suppose

$$
\begin{array}{r}
-g\left(p_{i}-m-\lambda\left(r_{i}-p_{i}\right)\right)-(1+\lambda)\left(p_{i}-s\right) g^{\prime}\left(p_{i}-m-\lambda\left(r_{i}-p_{i}\right)\right)<0 \\
-g\left(p_{i}-\lambda\left(r_{i}-p_{i}\right)\right)-(1+\lambda)\left(p_{i}-s\right) g^{\prime}\left(p_{i}-\lambda\left(r_{i}-p_{i}\right)\right)<0
\end{array}
$$

throughout the paper.

Assumption 2 ensures the omnichannel retailer's discounted total profit (10) to be concave with respect to retail price $p$ and ending inventory level $E$, and thus, the optimal $p$ and $E$ are unique. Moreover, the following lemmas can be obtained.
Lemma 2. $L_{j}\left(p_{i}, r_{i}\right), j=1,2,3$, is decreasing in $p_{i}$ and increasing in $r_{i}$. Thus, for each fixed reference price $r_{i}$, $L_{j}\left(p_{i}, r_{i}\right)=0, j=1,2,3$ has an unique solution $\bar{p}_{i}^{j *}\left(r_{i}\right)$.

Lemma 3. $\left(\partial A\left(p_{i}\right) / \partial p_{i}\right)=L_{1}\left(p_{i}, r_{i}\right), \quad\left(\partial B\left(p_{i}\right) / \partial p_{i}\right)=$ $L_{3}\left(p_{i}, r_{i}\right)$, and $\left(\partial\left[\lambda_{1} A\left(p_{i}, r_{i}\right)+\lambda_{2} B\left(p_{i}, r_{i}\right)\right] / \partial p_{i}\right)=L_{2}\left(p_{i}, r_{i}\right)$. 
TABLE 2: Summary of notations.

\begin{tabular}{|c|c|}
\hline Notation & Description \\
\hline \multicolumn{2}{|l|}{ Decision } \\
\hline$p_{i}$ & The omnichannel retailer's retail price in the $i$ th period \\
\hline$E_{i}$ & The ending inventory level in the $i$ th period \\
\hline \multicolumn{2}{|r|}{ 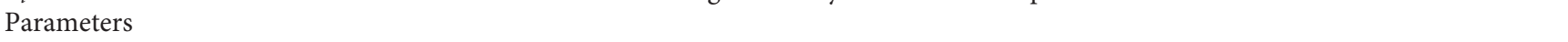 } \\
\hline$D_{i}$ & The demand rate in the $i$ th period \\
\hline$\Pi(\cdot)$ & The omnichannel retailer's discounted total profit over the infinite horizon \\
\hline$\pi_{i}(\cdot)$ & The omnichannel retailer's total profit in the $i$ th period \\
\hline$z$ & The discount factor $(0<z<1)$ \\
\hline$\lambda, \gamma$ & $\begin{array}{l}\text { The reference price effects coefficient implies the sensitivity of consumers to the gap between the reference price and the retail } \\
\text { price. The demand is called loss neutral if } \lambda=\gamma \text {, loss averse if } \lambda>\gamma \text {, and loss seeking if } \lambda<\gamma\end{array}$ \\
\hline$\alpha$ & The memory factor $(0 \leq \alpha<1)$ \\
\hline$v_{i}$ & $\begin{array}{l}\text { The valuation of the product by the consumer in the } i \text { th period, random values that follow distribution } G(\cdot) \text { and density } g(\cdot) \text {, and } \\
\qquad \bar{G}(\cdot)=1-G(\cdot)\end{array}$ \\
\hline$c$ & The unit inventory and procurement cost \\
\hline$m$ & The unit shipping fee \\
\hline$t$ & The unit travelling cost of consumers to visit the store \\
\hline$s$ & The salvage price for a leftover unit \\
\hline$l$ & The cross-selling benefit \\
\hline$\sigma$ & $\begin{array}{c}\text { The fraction of online consumers choosing to BOPS, and } 1-\sigma \text { is the fraction of online consumers choosing to buy online } \\
\text { directly }\end{array}$ \\
\hline$\rho$ & $\begin{array}{l}\text { The fraction of the incremental demand (brought by the omnichannel strategy) coming from the online market, and } 1-\rho \text { is the } \\
\text { fraction of the incremental demand coming from offline market }\end{array}$ \\
\hline$k$ & The fraction of the market demand served under the single online channel strategy \\
\hline
\end{tabular}

\section{Structural Analysis of the Optimal Omnichannel Strategies}

In this section, we analyze structural properties of the omnichannel retailer's optimal pricing and ending inventory level. In what follows, we first analyze the case of loss neutral demand. Secondly, we extend the loss neutral demand to the other case of loss averse demand.

4.1. Loss Neutral Demand. In this subsection, we analyze the omnichannel retailer's optimal pricing and ending inventory level when demand is loss neutral. First, in order to prove the uniqueness of the optimal pricing and ending inventory level, the concavity of $\Pi(P, E)$ is needed.

Proposition 1. $\Pi(\mathrm{P}, \mathrm{E})$ is concave in $p_{i}$ and $E_{i}$, and thus, the optimal $p_{i}^{*}$ and $E_{i}^{*}$ in the ith period are unique.

Next, we investigate the initial reference price $r_{1}$ on the optimal pricing and ending inventory level decisions, and the following lemma is needed.

Lemma 4. If $\beta_{0}-\beta_{1} \bar{p}-\lambda(\bar{p}-\underline{p})>\max \left\{M_{1}, M_{2}\right\}$, where

$$
\begin{aligned}
& M_{1}=\frac{a}{1-a}\left(\beta_{1}+\lambda\right) \frac{\lambda_{1} A\left(\bar{p}, r_{i}\right)+\lambda_{2} B\left(\bar{p}, r_{i}\right)-(c-s)-(h T / 2)}{L_{2}\left(\bar{p}, r_{i}\right)} \\
& M_{2}=\frac{\left(\beta_{1}+\lambda\right)}{(1-a) T} \cdot \frac{\left[\lambda_{1}(\bar{p}-s) g\left(\bar{p}-m-\lambda\left(r_{i}-\bar{p}\right)\right)+\lambda_{2}(\bar{p}-s) g\left(\bar{p}-\lambda\left(r_{i}-\bar{p}\right)\right)\right]+a T\left[\lambda_{1} A\left(\bar{p}, r_{i}\right)+\lambda_{2} B\left(\bar{p}, r_{i}\right)-(c-s)-(h T / 2)\right]}{L_{2}\left(\bar{p} r_{i}\right)},
\end{aligned}
$$

then

$$
\begin{aligned}
& \phi^{\lambda}\left(p_{i}, r_{i}, E_{i}\right)>a\left(\beta_{1}+\lambda\right) T \frac{\lambda_{1} A\left(p_{i}, r_{i}\right)+\lambda_{2} B\left(p_{i}, r_{i}\right)-(c-s)-(h T / 2)}{L_{2}\left(p_{i}, r_{i}\right)}, \\
& \phi^{\lambda}\left(p_{i}, r_{i}, E_{i}\right)>\left(\beta_{1}+\lambda\right) \frac{\left\{\left[\lambda_{1}\left(p_{i}-s\right) g\left(p_{i}-m-\lambda\left(r_{i}-p_{i}\right)\right)+\lambda_{2}\left(p_{i}-s\right) g\left(p_{i}-\lambda\left(r_{i}-p_{i}\right)\right)\right]+a T\left[\lambda_{1} A\left(p_{i}, r_{i}\right)+\lambda_{2} B\left(p_{i}, r_{i}\right)-(c-s)-(h T / 2) / 2\right]\right\}}{L_{2}\left(p_{i}, r_{i}\right)} .
\end{aligned}
$$


Proposition 2. When the demand is loss neutral, then $\left\{p_{i}^{*}\right\}_{i=1}^{\infty}$ and $\left\{E_{i}^{*}\right\}_{i=1}^{\infty}$ both increase as $r_{1}$ increases if $\beta_{0}-\beta_{1} \bar{p}-\lambda(\bar{p}-\underline{p})>\max \left\{M_{1}, M_{2}\right\}$.

Proposition 2 indicates that both the optimal price and ending inventory level sequences $\left\{p_{i}^{*}\right\}_{i=1}^{\infty}$ and $\left\{E_{i}^{*}\right\}_{i=1}^{\infty}$ increase with the initial reference price $r_{1}$. This can be intuitively illustrated as follows: With the increase of consumers' initial reference price, i.e., when consumers' initial valuation of the product increases, the demand will increase and the optimal price will rise as well. The omnichannel retailer orders more to raise the inventory level so as to meet the demand as much as possible. As a result, the ending inventory level will increase. The following result shows the monotonicity behavior of the optimal decisions depending on the initial reference price.

Proposition 3. When the demand is loss neutral, the following results hold: (i) If $p_{1}^{*}>r_{1}$, then $\left\{p_{i}^{*}\right\}_{i=1}^{\infty}$ and $\left\{E_{i}^{*}\right\}_{i=1}^{\infty}$ are both increasing

(ii) If $p_{1}^{*}<r_{1}$, then $\left\{p_{i}^{*}\right\}_{i=1}^{\infty}$ and $\left\{E_{i}^{*}\right\}_{i=1}^{\infty}$ are both decreasing

(iii) If $p_{1}^{*}=r_{1}$, then $r_{1}=p_{1}^{*}=p_{2}^{*}=p_{3}^{*}=\cdots$ and $E_{1}^{*}=E_{2}^{*}=E_{3}^{*}=\cdots$

Proposition 3 shows that both the optimal price and ending inventory level sequences $\left\{p_{i}^{*}\right\}_{i=1}^{\infty}$ and $\left\{E_{i}^{*}\right\}_{i=1}^{\infty}$ are monotonic in the same direction depending on the initial reference price $r_{1}$. Thus, both $\left\{p_{i}^{*}\right\}_{i=1}^{\infty}$ and $\left\{E_{i}^{*}\right\}_{i=1}^{\infty}$ are convergent due to their boundness. Let $p_{e}$ and $E_{e}$ denote the equilibrium selling price and ending inventory level when demand is loss neutral. Then, $p_{e}$ and $E_{e}$ can be characterized via the following result.

Proposition 4. If an interior equilibrium exists, pe and Ee can be simultaneously determined by

$$
\begin{aligned}
L_{2}\left(p_{e}, p_{e}\right)\left(\frac{\lambda_{1} A\left(p_{e}, p_{e}\right)+\lambda_{2} B\left(p_{e}, p_{e}\right)+(h T / 2)}{\lambda_{1} A\left(p_{e}, p_{e}\right)+\lambda_{2} B\left(p_{e}, p_{e}\right)-(c-s)-(h T / 2)}\right)^{(1 / a)}-1 \\
=\frac{\left(\beta_{1}+\lambda(1-z / 1-\alpha z)\right)\left[\lambda_{1} A\left(p_{e}, p_{e}\right)+\lambda_{2} B\left(p_{e}, p_{e}\right)-(c-s)-(h T / 2)\right]}{(1-a)\left(\beta_{0}-\beta_{1} p_{e}\right)} \\
\quad \times\left[\left(\frac{\lambda_{1} A\left(p_{e}, p_{e}\right)+\lambda_{2} B\left(p_{e}, p_{e}\right)+(h T / 2)}{\lambda_{1} A\left(p_{e}, p_{e}\right)+\lambda_{2} B\left(p_{e}, p_{e}\right)-(c-s)-(h T / 2)}\right)^{(1 / a)}-\left(\frac{\lambda_{1} A\left(p_{e}, p_{e}\right)+\lambda_{2} B\left(p_{e}, p_{e}\right)+(h T / 2)}{\lambda_{1} A\left(p_{e}, p_{e}\right)+\lambda_{2} B\left(p_{e}, p_{e}\right)-(c-s)-(h T / 2)}\right)\right], \\
E_{e}=\left[\frac{(1-a) T\left(\beta_{0}-\beta_{1} p_{e}\right)}{\left(\lambda_{1} A\left(p_{e}, p_{e}\right)+\lambda_{2} B\left(p_{e}, p_{e}\right)+(h T / 2) / \lambda_{1} A\left(p_{e}, p_{e}\right)+\lambda_{2} B\left(p_{e}, p_{e}\right)-(c-s)-(h T / 2)\right)^{(1-a / a)}-1}\right]
\end{aligned}
$$

respectively.

The next proposition characterizes the impact of the strength of reference price effects coefficient $(\lambda)$, memory factor $(\alpha)$, unit shipping fee $m$, and cross-selling benefit $l$ on the optimal pricing and ending inventory level.

Proposition 5. If an interior equilibrium exists, then

(i) $p_{e}$ and $E_{e}$ are both decreasing in $\lambda$

(ii) $p_{e}$ and $E_{e}$ are both decreasing in $\alpha$

(iii) $p_{e}$ and $E_{e}$ are both increasing in $m$

(iv) $p_{e}$ and $E_{e}$ are both increasing in $l$

Proposition 5 indicates that both equilibrium selling price $p_{e}$ and ending inventory level $E_{e}$ decrease with the initial reference price $\lambda$ and $\alpha$. This can be intuitively interpreted as follows: First, when $\lambda$ increases, it implies that consumers are more sensitive to the gap between the selling price and the reference price. The retailer should reduce the selling price in order to make the selling price closer to the consumers' reference price and reduce the inventory level at the same time. Thus, $p_{e}$ and $E_{e}$ are both decreasing. Second, when $\alpha$ increases, consumers have a long memory and the past price effect is larger. This means that consumers adapt to the new price information at a lower rate and behave less loyaly; then, the retailer should decrease its selling price while reducing the inventory level. Hence, the equilibrium selling price $p_{e}$ and ending inventory level $E_{e}$ also decrease. Third, since the forward shipping fee $m$ is paid by the retailer, if the forward shipping fee increases, the selling price will naturally increase. Moreover, the high return shipping fee $m$ will reduce the consumers' desire to buy, which leads to an increase in the retailer's ending inventory. Fourth, when the cross-selling benefit $l$ increases, it indicates that there are more consumers who patronize the physical stores (including offline consumers and BOPS consumers), and retailers can increase inventory to meet the needs of these consumers. Additionally, the retailer will increase the corresponding service cost for the extreme experience service provided by the physical store, which will make the retailer increase the sales price of goods. Combining Propositions 3-5, we can get the following conclusion.

Proposition 6. If an interior equilibrium exists, then

(i) If $p_{1}^{*}>r_{1}$, then $\left\{p_{i}^{*}\right\}_{i=1}^{\infty}$ and $\left\{E_{i}^{*}\right\}_{i=1}^{\infty}$ both increase monotonically and converge to $p_{e}$ and $E_{e}$, respectively 
(ii) If $p_{1}^{*}>r_{1}$, then $\left\{p_{i}^{*}\right\}_{i=1}^{\infty}$ and $\left\{E_{i}^{*}\right\}_{i=1}^{\infty}$ both decrease monotonically and converge to $p_{e}$ and $E_{e}$, respectively

(iii) If $p_{1}^{*}=r_{1}$, then $p_{e}=p_{1}^{*}=p_{2}^{*}=p_{3}^{*}=\cdots$ and $E_{e}=E_{1}^{*}=E_{2}^{*}=E_{3}^{*}=\cdots$
4.2. Loss Averse Demand. In this section, we extend the case of loss neutral demand to that of loss averse, i.e., $\lambda>\gamma$. Following the analysis similar to that in $[24,29]$, for $\mathrm{P}=\left\{p_{1}, p_{2}, p_{3}, \ldots\right\}, \mathrm{E}=\left\{E_{1}, E_{2}, E_{3}, \ldots\right\}$, and $\Omega=\{(\mathrm{P}, \mathrm{E}): p \leq$ $\left.p_{i} \leq \bar{p}_{i}^{2 *}\left(r_{i}\right)<\bar{p}, 0 \leq E_{i} \leq \bar{E}\right\}$, the profit-maximizing problem for the loss averse demand is formulated as follows:

$$
\begin{aligned}
\max _{(\mathrm{P}, \mathrm{E}) \in \Omega} \Pi(\mathrm{P}, \mathrm{E}) & =\max _{(\mathrm{P}, \mathrm{E}) \in \Omega} \sum_{i=1}^{\infty} z^{i-1} \pi\left(p_{i}, r_{i}, E_{i}\right), \\
& =\max _{(\mathrm{P}, \mathrm{E}) \in \Omega} \sum_{i=1}^{\infty} z^{i-1} \min \left\{\pi^{\lambda}\left(p_{i}, r_{i}, E_{i}\right), \pi^{\gamma}\left(p_{i}, r_{i}, E_{i}\right)\right\}, \\
& =\min \left\{\max _{(\mathrm{P}, \mathrm{E}) \in \Omega} \Pi^{\lambda}(\mathrm{P}, \mathrm{E}), \max _{(\mathrm{P}, \mathrm{E}) \in \Omega} \Pi^{\gamma}(\mathrm{P}, \mathrm{E})\right\},
\end{aligned}
$$

where $\Pi^{x}(\mathrm{P}, \mathrm{E})=\sum_{i=1}^{\infty} z^{i-1} \pi^{x}\left(p_{i}, r_{i}, E_{i}\right), x=\lambda$ or $\gamma$, and

$$
\begin{aligned}
\pi^{x}\left(p_{i}, r_{i}, E_{i}\right)= & {\left[\lambda_{1} A\left(p_{i}, r_{i}\right)+\lambda_{2} B\left(p_{i}, r_{i}\right)-(c-s)-\frac{h T}{2}\right] \cdot\left[\phi^{x}\left(p_{i}, r_{i}, E_{i}\right)\right]^{(1 / 1-a)} } \\
& -\left[\lambda_{1} A\left(p_{i}, r_{i}\right)+\lambda_{2} B\left(p_{i}, r_{i}\right)+\frac{h T}{2}\right] E_{i}, \quad x=\lambda \text { or } \gamma, \\
\phi^{x}\left(p_{i}, r_{i}, E_{i}\right)= & E_{i}^{1-a}+(1-a) T\left[\beta_{0}-\beta_{1} p_{i}-x\left(p_{i}-r_{i}\right)\right] .
\end{aligned}
$$

Similar to the analysis in Section 4.1, we first prove the uniqueness of the optimal pricing and ending inventory level.
Proposition 7. The omnichannel retailer's discounted total profit (16) is concave in $p_{i}$ and $E_{i}$, and thus, the optimal $p_{i}^{*}$ and $E_{i}^{*}$ in the ith period are unique.

Since

$$
\begin{aligned}
& \pi^{\lambda}\left(p_{i}, r_{i}, E_{i}\right)-\pi^{\gamma}\left(p_{i}, r_{i}, E_{i}\right), \\
& \quad= \begin{cases}{\left[\lambda_{1} A\left(p_{i}, r_{i}\right)+\lambda_{2} B\left(p_{i}, r_{i}\right)-(c-s)-\frac{h T}{2}\right]\left\{\left[\phi^{\lambda}\left(p_{i}, r_{i}, E_{i}\right)\right]^{(1 / 1-a)}-\left[\phi^{\gamma}\left(p_{i}, r_{i}, E_{i}\right)\right]^{(1 / 1-a)}\right\}<0,} & p_{i}>r_{i}, \\
0, & p_{i}=r_{i}, \\
{\left[\lambda_{1} A\left(p_{i}, r_{i}\right)+\lambda_{2} B\left(p_{i}, r_{i}\right)-(c-s)-\frac{h T}{2}\right]\left\{\left[\phi^{\lambda}\left(p_{i}, r_{i}, E_{i}\right)\right]^{(1 / 1-a)}-\left[\phi^{\gamma}\left(p_{i}, r_{i}, E_{i}\right)\right]^{(1 / 1-a)}\right\}>0,} & p_{i}<r_{i},\end{cases}
\end{aligned}
$$

it follows from Proposition 3 that both the selling price $\left\{p_{i}^{*}\right\}_{i=1}^{\infty}$ and ending inventory level $\left\{E_{i}^{*}\right\}_{i=1}^{\infty}$ are monotonic in the same direction as the reference price path. Then, both $\left\{p_{i}^{*}\right\}_{i=1}^{\infty}$ and $\left\{E_{i}^{*}\right\}_{i=1}^{\infty}$ are convergent due to their boundness. Let $p_{e}^{x}$ and $E_{e}^{x}$ denote the equilibrium selling price and ending inventory level when demand is loss averse, $x=\lambda$ or $\gamma$. Moreover, since $\lambda>\gamma$, $p_{e}^{\lambda}<p_{e}^{\gamma}$ and $E_{e}^{\lambda}<E_{e}^{\gamma}$ by applying Proposition 6 . We can, thus, obtain the following structural properties of the optimal decisions for the case of loss averse demand.

Proposition 8. If an interior equilibrium exists, then

(i) If $p_{e}^{\gamma}<r_{1}$, then $\max _{(\mathrm{P}, \mathrm{E}) \in \Omega} \Pi(\mathrm{P}, \mathrm{E})=\max _{(\mathrm{P}, \mathrm{E}) \in \Omega}$ $\Pi^{\gamma}(\mathrm{P}, \mathrm{E})$, and $\left\{p_{i}^{*}\right\}_{i=1}^{\infty}$ and $\left\{E_{i}^{*}\right\}_{i=1}^{\infty}$ both decrease 
monotonically and converge to $p_{e}^{\gamma}$ and $E_{e}^{\gamma}$, respectively

(ii) If $p_{e}^{\lambda}>r_{1}$, then $\max _{(\mathrm{P}, \mathrm{E}) \in \Omega} \Pi(\mathrm{P}, \mathrm{E})=\max _{(\mathrm{P}, \mathrm{E}) \in \Omega}$ $\Pi^{\lambda}(\mathrm{P}, \mathrm{E})$, and $\left\{p_{i}^{*}\right\}_{i=1}^{\infty}$ and $\left\{E_{i}^{*}\right\}_{i=1}^{\infty}$ both increase monotonically and converge to $p_{e}^{\lambda}$ and $E_{e}^{\lambda}$, respectively (iii) If $p_{e}^{\lambda} \leq r_{1} \leq p_{e}^{\gamma}$, then $\max _{(\mathrm{P}, \mathrm{E}) \in \Omega} \Pi(\mathrm{P}, \mathrm{E})=\max _{(\mathrm{P}, \mathrm{E}) \in \Omega}$ $\Pi^{\lambda}(\mathrm{P}, \mathrm{E})=\max _{(\mathrm{P}, \mathrm{E}) \in \Omega} \quad \Pi^{\gamma}(\mathrm{P}, \mathrm{E}), \quad r_{1}=p_{1}^{*}=p_{2}^{*}=$ $p_{3}^{*}=\cdots$, and

$$
E_{i}=\left[\frac{(1-a) T\left(\beta_{0}-\beta_{1} r_{1}\right)}{\left(\lambda_{1} A\left(p_{e}, p_{e}\right)+\lambda_{2} B\left(p_{e}, p_{e}\right)+(h T / 2) / \lambda_{1} A\left(p_{e}, p_{e}\right)+\lambda_{2} B\left(p_{e}, p_{e}\right)-(c-s)-(h T / 2)\right)^{(1-a / a)}-1}\right]^{(1 / 1-a)}, i=1,2,3, \ldots .
$$

\section{Numerical Analysis}

In this section, we carry out several numerical experiments to illustrate the abovementioned theoretical results and gain some managerial insights. The following analysis considers the loss of neutral consumers because, according to (16), the situation when consumers are loss aversion can be similarly analyzed. All experiments below are performed in MATLAB R2014b on a laptop with an Intel(R) Core (TM) i5-7200U central processing unit (CPU) $(2.50 \mathrm{GHz}, 2.70 \mathrm{GHz})$ and 8.0 GB of RAM running 64 bit Windows 10 Enterprise.

We consider an omnichannel inventory system with the following initial parameter values: $\beta_{0}=160, \beta_{1}=2, c=10$, $h=2, s=1, m=1, l=2, \alpha=0.8, a=0.2, z=0.6, \sigma=0.3$, $k=0.6, \rho=0.6, T=1, p=20, \bar{p}=40$, and $v_{i} \sim U[10,30]$. The optimal equilibrium price, ending inventory level, and optimal discounted total profit for the different values of $\lambda$ and $r_{1}$ can be obtained by Proposition 4 , which are presented in Table 3. Furthermore, the sensitivity analysis of the key system parameters, including the memory factor $\alpha$, the ratio of BOPS consumers $\sigma$, the cross-selling profit $l$, and the shipping fee $m$, is presented on the optimal equilibrium price $p_{e}$ and ending inventory level $E_{e}$, as well as the optimal discounted total profit $\Pi\left(\mathrm{P}^{*}, \mathrm{E}^{*}\right)$, and the corresponding computational results are shown in Tables 4-7.

As shown in Table 3, the optimal equilibrium price $p_{e}$ and ending inventory level $E_{e}$ both are decreasing in $\lambda$, which is consistent with Proposition 5 (i). Furthermore, the optimal discounted total profit, $\Pi\left(\mathrm{P}^{*}, \mathrm{E}^{*}\right)$, increases with the initial reference price $r_{1}$, which is also consistent with Lemma 1 . This can be intuitively illustrated as follows. When $\lambda$ is large, which means that the consumers are more sensitive to the gap between the consumers' reference price and the retailer's actual selling price is large, the retailer should decrease the selling price in order to reduce this gap, stimulating demand. This increases the retailer's profit $\Pi\left(\mathrm{P}^{*}, \mathrm{E}^{*}\right)$ and reduces the ending inventory level $E_{e}$.

Table 4 presents the impact of memory factor $\alpha$ on the optimal equilibrium price $p_{e}$, ending inventory level $E_{e}$ and optimal discounted total profit $\Pi\left(\mathrm{P}^{*}, \mathrm{E}^{*}\right)$. As shown in Table 4 , the optimal equilibrium price $p_{e}$ and ending inventory level $E_{e}$ both are decreasing in $\alpha$, which is consistent with Proposition 5 (ii). We can also see from Table 4 that when the initial reference price $r_{1}$ is high, the retailer's profit increases with $\alpha$. The intuition is that when $\alpha$ is large, the consumers have a long-term memory of the initial reference price $r_{1}$. If the current price is high enough, consumers will not be willing to buy. Hence, the retailer should decrease the selling price below the initial reference price $r_{1}$ in order to reduce the gap between the consumers' reference price and the retailer's actual selling price, thus stimulating demand, which increases the retailer's total profit $\Pi\left(\mathrm{P}^{*}, \mathrm{E}^{*}\right)$ and reduces the ending inventory level $E_{e}$.

Table 5 provides the impact of the ratio of BOPS consumers' $\sigma$ on the optimal equilibrium price $p_{e}$, ending inventory level $E_{e}$, and optimal discounted total profit $\Pi\left(\mathrm{P}^{*}, \mathrm{E}^{*}\right)$. It follows from Table 5 that the optimal equilibrium price $p_{e}$ and ending inventory level $E_{e}$ both are decreasing in $\sigma$. This implies that the increase of the ratio of consumers who choose BOPS will make the retailer reduce the selling price, which will not only attract more consumers to patronize the physical store but also make the retailer earn more cross-selling profit, thus increasing the total profit $\Pi\left(\mathrm{P}^{*}, \mathrm{E}^{*}\right)$.

Table 6 shows the impact of shipping fee $m$ on the optimal equilibrium price $p_{e}$, ending inventory level $E_{e}$ and optimal discounted total profit $\Pi\left(\mathrm{P}^{*}, \mathrm{E}^{*}\right)$. As shown in Table 6 , the optimal equilibrium price $p_{e}$ and ending inventory level $E_{e}$ both are increasing in $m$, which is consistent with Proposition 5 (iii). The intuitive explanation is that when the shipping fee increases, the retailer will inevitably increase the selling price, which in turn will reduce the demand and increase the ending inventory level, which is not conducive to the retailer's profit $\Pi\left(\mathrm{P}^{*}, \mathrm{E}^{*}\right)$.

Table 7 presents the impact of cross-selling profit $l$ on the optimal equilibrium price $p_{e}$, ending inventory level $E_{e}$ and optimal discounted total profit $\Pi\left(\mathrm{P}^{*}, \mathrm{E}^{*}\right)$. As shown in Table 7 , the optimal equilibrium price $p_{e}$ and ending inventory level $E_{e}$ both are increasing in $l$, which is consistent with Proposition 5 (iv). Table 5 implies that when the cross-selling profit increases, if the retailer increases the selling price, the demand will be restrained, resulting in the increase of ending inventory and the decrease of profit $\Pi\left(\mathrm{P}^{*}, \mathrm{E}^{*}\right)$.

\section{Managerial Insights}

In this section, some managerial insights are derived from the numerical analysis, which can be adopted by an 
TABLE 3: The optimal solutions with respect to different values of $\lambda$ and $r 1$.

\begin{tabular}{lcccc}
\hline$\lambda$ & $r_{1}$ & $\Pi\left(\mathrm{P}^{*}, \mathrm{E}^{*}\right)$ & $p_{e}$ & $E_{e}$ \\
\hline 1 & 35 & 108.66 & 30.8677 & 1.5071 \\
1 & 40 & 1197.4 & 30.8677 & 1.5071 \\
1 & 45 & 3622.7 & 30.8677 & 1.5071 \\
1 & 48 & 5791.5 & 30.8677 & 1.5071 \\
1 & 55 & 13111 & 30.8677 & 1.5071 \\
1.25 & 35 & 247.87 & 30.8341 & 1.4344 \\
1.25 & 40 & 2163.5 & 30.8341 & 1.4344 \\
1.25 & 45 & 6295.4 & 30.8341 & 1.4344 \\
1.25 & 48 & 9955.7 & 30.8341 & 1.4344 \\
1.25 & 55 & 22234 & 30.8341 & 1.4344 \\
1.50 & 35 & 443.80 & 30.8066 & 1.3755 \\
1.50 & 40 & 3445.4 & 30.8066 & 1.3755 \\
1.50 & 45 & 9794.8 & 30.8066 & 1.3755 \\
1.50 & 48 & 15387 & 30.8066 & 1.3755 \\
1.50 & 55 & 34072 & 30.8066 & 1.3755 \\
\hline
\end{tabular}

TABle 4: Effect of change in $\alpha$ for the dynamic model with $\lambda=\gamma=1.25$.

\begin{tabular}{ccccc}
\hline$r_{1}$ & $\alpha$ & $\Pi\left(\mathrm{P}^{*}, \mathrm{E}^{*}\right)$ & $p_{e}$ & $E_{e}$ \\
\hline 35 & 0.750 & 244.59 & 30.8426 & 1.4527 \\
35 & 0.775 & 246.21 & 30.8384 & 1.4437 \\
35 & 0.800 & 247.87 & 30.8341 & 1.4344 \\
35 & 0.825 & 249.57 & 30.8297 & 1.4249 \\
35 & 0.850 & 251.35 & 30.8251 & 1.4151 \\
45 & 0.750 & 6280.3 & 30.8426 & 1.4527 \\
45 & 0.775 & 6287.7 & 30.8384 & 1.4437 \\
45 & 0.800 & 6295.4 & 30.8341 & 1.4344 \\
45 & 0.825 & 6303.2 & 30.8297 & 1.4249 \\
45 & 0.850 & 6311.3 & 30.8251 & 1.4151 \\
55 & 0.750 & 22208 & 30.8426 & 1.4527 \\
55 & 0.775 & 22221 & 30.8384 & 1.4437 \\
55 & 0.800 & 22234 & 30.8341 & 1.4344 \\
55 & 0.825 & 22247 & 30.8297 & 1.4249 \\
55 & 0.850 & 22262 & 30.8251 & 1.4151 \\
\hline
\end{tabular}

TABle 5: Effect of change in $\sigma$ for the dynamic model with $\lambda=\gamma=1.25$.

\begin{tabular}{ccccc}
\hline$r_{1}$ & $\sigma$ & $\Pi\left(\mathrm{P}^{*}, \mathrm{E}^{*}\right)$ & $p_{e}$ & $E_{e}$ \\
\hline 35 & 0.1 & 102.47 & 31.0677 & 1.9531 \\
35 & 0.3 & 247.87 & 30.8341 & 1.4344 \\
35 & 0.5 & 459.16 & 30.5985 & 0.9473 \\
35 & 0.7 & 744.14 & 30.3608 & 0.5031 \\
35 & 0.9 & 1105.9 & 30.1208 & 0.1282 \\
45 & 0.1 & 4104.3 & 31.0677 & 1.9531 \\
45 & 0.3 & 6295.4 & 30.8341 & 1.4344 \\
45 & 0.5 & 8735.9 & 30.5985 & 0.9473 \\
45 & 0.7 & 11424 & 30.3608 & 0.5031 \\
45 & 0.9 & 14346 & 30.1208 & 0.1282 \\
55 & 0.1 & 15110 & 31.0677 & 1.9531 \\
55 & 0.3 & 22234 & 30.8341 & 1.4344 \\
55 & 0.5 & 29779 & 30.5985 & 0.9473 \\
55 & 0.7 & 37731 & 30.3608 & 0.5031 \\
55 & 0.9 & 46059 & 30.1208 & 0.1282 \\
\hline
\end{tabular}

TABLE 6: Effect of change in $m$ for the dynamic model with $\lambda=\gamma=1.25$.

\begin{tabular}{ccccc}
\hline$r_{1}$ & $m$ & $\Pi\left(\mathrm{P}^{*}, \mathrm{E}^{*}\right)$ & $p_{e}$ & $E_{e}$ \\
\hline 35 & 1 & 247.87 & 30.8341 & 1.4344 \\
35 & 2 & 149.63 & 31.1084 & 2.0644 \\
35 & 3 & 66.290 & 31.3900 & 2.7163 \\
35 & 4 & 1.1265 & 31.6790 & 3.4398 \\
35 & 5 & -42.368 & 31.9753 & 4.2151 \\
45 & 1 & 6295.4 & 30.8341 & 1.4344 \\
45 & 2 & 5812.8 & 31.1084 & 2.0644 \\
45 & 3 & 5317.3 & 31.3900 & 2.7163 \\
45 & 4 & 4820.2 & 31.6790 & 3.4398 \\
45 & 5 & 4322.5 & 31.9753 & 4.2151 \\
55 & 1 & 22234 & 30.8341 & 1.4344 \\
55 & 2 & 21386 & 31.1084 & 2.0644 \\
55 & 3 & 20492 & 31.3900 & 2.7163 \\
55 & 4 & 19575 & 31.6790 & 3.4398 \\
55 & 5 & 18632 & 31.9753 & 4.2151 \\
\hline
\end{tabular}

TABle 7: Effect of change in $l$ for the dynamic model with $\lambda=\gamma=1.25$.

\begin{tabular}{ccccc}
\hline$r_{1}$ & $l$ & $\Pi\left(\mathrm{P}^{*}, \mathrm{E}^{*}\right)$ & $p_{e}$ & $E_{e}$ \\
\hline 40 & 2 & 2163.5 & 30.8341 & 1.4344 \\
40 & 3 & 494.88 & 32.6087 & 1.4366 \\
40 & 4 & 294.13 & 33.0113 & 7.1432 \\
40 & 5 & 89.083 & 33.4010 & 8.3197 \\
40 & 6 & -64.894 & 33.7791 & 9.4956 \\
45 & 2 & 6295.4 & 30.8341 & 1.4344 \\
45 & 3 & 2983.4 & 32.6087 & 1.4366 \\
45 & 4 & 2723.9 & 33.0113 & 7.1432 \\
45 & 5 & 2184.4 & 33.4010 & 8.3197 \\
45 & 6 & 1697.9 & 33.7791 & 9.4956 \\
55 & 2 & 22234 & 30.8341 & 1.4344 \\
55 & 3 & 17057 & 32.6087 & 1.4366 \\
55 & 4 & 15386 & 33.0113 & 7.1432 \\
55 & 5 & 14188 & 33.4010 & 8.3197 \\
55 & 6 & 13042 & 33.7791 & 9.4956 \\
\hline
\end{tabular}

omnichannel retailer to formulate its pricing and ending inventory strategies with the reference price effects.

The parameter $\lambda$ has a negative impact on selling price and positive impact on profit. When the reference price effects on demand are great, which means that the gap between the reference price and the retailer's actual selling price is large, the retailer should adopt low selling price to reduce this gap and stimulate demand so that the retailer can raise its profit and reduce the ending inventory level.

The memory parameter $\alpha$ has a negative impact on selling price and positive impact on profit. As $\alpha$ increases, consumers have a long-term memory of the initial reference price $r_{1}$. If the current selling price is high enough, consumers will not be willing to buy. Hence, the retailer should decrease the selling price in order to reduce the gap between the reference price and the retailer's selling price, thus stimulating demand, which helps to increase the retailer's profit and reduce the ending inventory level. 
When the BOPS is considered, as the ratio of BOPS consumers $\sigma$ increases, the retailer should adopt a low-price strategy, which will not only attract more consumers to patronize the physical store by means of the advantages of in-store experience but also make the retailer earn more cross-selling profit, thus increasing its profit. In addition, Table 5 indicates that the retailer should not increase the selling price when the cross-selling profit increases because this will restrain the demand. Finally, the shipping fee $m$ has a negative impact on selling price and profit. The reason is that a higher unit shipping fee can decrease the consumers' willingness to pay for the product, which in turn will reduce the demand and increase the ending inventory level, which is not conducive to the retailer's profit.

\section{Conclusions}

Our research complements the existing research stream in coordinating pricing and inventory replenishment decisions under an omnichannel retail environmental by taking into the consideration of consumers' reference price effects. Specifically, this paper considers an omnichannel retailer's multiperiod pricing and inventory retail operations under reference price effects in which consumers can cancel their order before payment and return the product after payment if the product does not meet their expectation. The omnichannel retailer's optimal equilibrium pricing and ending inventory level are derived under the reference price effects by maximizing the discounted total profit over the infinite planning horizon, where the optimal decisions we discussed are under two scenarios: loss neutrality and loss aversion. In addition, the impact of system parameters on the optimal price and ending inventory level is studied. Our main results are summarized as follows. First, our analysis shows that the convergence of the pricing and ending inventory level toward their equilibrium is from above or below, depending on the relative location of the initial reference price with respect to the unique equilibrium price. Second, we investigate how key system parameters affect the optimal decisions. When consumers are more sensitive to the gap between the selling price and the reference price or consumers have a long memory of the past price, both equilibrium selling price $p_{e}$ and ending inventory level $E_{e}$ decrease. Furthermore, when the shipping fee $m$ or the cross-selling benefit $l$ increases, both equilibrium selling price $p_{e}$ and ending inventory level $E_{e}$ increase. This research fills in the gap of behavioral operation management in the study of pricing and inventory in omnichannel retail operations.

Though this paper has identified the effects of reference price on the coordination of pricing and inventory decisions for an omnichannel retailer, there are still some shortcomings that can be investigated in the future. First, this paper analyzes the pricing and inventory decisions of an omnichannel retailer under consumers' reference price effects, unaware of the influence of loss aversion on the omnichannel retailer. An interesting future research topic is to examine the pricing and inventory decisions for considering the reference point and loss aversion of an omnichannel retailer. Second, in our study, the customers' reference price can be observed by retailers. However, the information on the reference price is difficult to obtain in reality. Therefore, demand learning can be incorporated into formulating pricing and inventory strategies in the presence of the reference price effects under the omnichannel environment. Third, the government subsidy is necessary because the high shipping fee will increase the selling price, thus restraining the increase of demand and profit (see, for example, [30]). Hence, government subsidy for the shipping fee is another factor that can be incorporated into formulating pricing and inventory strategies in the presence of the reference price effects under the omnichannel environment.

\section{Appendix}

Proof of Lemma 1. Since $\phi\left(p_{i}, r_{i}, E_{i}\right)$ is increasing in $r_{1}$, $\pi\left(p_{i}, r_{i}, E_{i}\right)$ is increasing in $r_{1}$. Thus, $\Pi(\mathrm{P}, \mathrm{E})=$ $\sum_{i=1}^{\infty} z^{i-1} \pi\left(p_{i}, r_{i}, E_{i}\right)$ is increasing in $r_{1}$.

Proof of Lemma 2. Since

$$
\begin{aligned}
& \frac{\partial L_{1}(p, r)}{\partial p}=-(1+\gamma)\left[g(p-m-\gamma(r-p))+(p-s)(1+\gamma) g^{\prime}(p-m-\gamma(r-p))\right], \\
& \frac{\partial L_{3}(p, r)}{\partial p}=-(1+\gamma)\left[g(p-\gamma(r-p))+(p-s)(1+\gamma) g^{\prime}(p-\gamma(r-p))\right], \\
& \frac{\partial L_{1}(p, r)}{\partial r}=\gamma\left[g(p-m-\gamma(r-p))+(p-s)(1+\gamma) g^{\prime}(p-m-\gamma(r-p))\right], \\
& \frac{\partial L_{3}(p, r)}{\partial r}=\gamma\left[g(p-\gamma(r-p))+(p-s)(1+\gamma) g^{\prime}(p-\gamma(r-p))\right],
\end{aligned}
$$


it follows from Assumption 2 that $\left(\partial L_{1}(p, r) / \partial p\right)<0$, $\left(\partial L_{3}(p, r) / \partial p\right)<0,\left(\partial L_{1}(p, r) / \partial r\right)>0$ and $\left(\partial L_{3}(p, r) / \partial r\right)>0$,

Proof of Proposition 1. Since which yields the results.

$$
\begin{aligned}
\frac{\partial \Pi(\mathrm{P}, \mathrm{E})}{\partial p_{i}^{2}}= & z^{i-1} \frac{\partial L_{2}\left(p_{i}, r_{i}\right)}{\partial p_{i}}\left\{\left[\phi^{\lambda}\left(p_{i}, r_{i}, E_{i}\right)\right]^{(1 / 1-a)}-E_{i}\right\} \\
& -z^{i-1}\left\{2\left(\beta_{1}+\lambda\right) T L_{2}\left(p_{i}, r_{i}\right)\left[\phi^{\lambda}\left(p_{i}, r_{i}, E_{i}\right)\right]^{(1 / 1-a)-1}\right. \\
& \left.+a\left(\beta_{1}+\lambda\right)^{2} T^{2}\left[\lambda_{1} A\left(p_{i}, r_{i}\right)+\lambda_{2} B\left(p_{i}, r_{i}\right)-(c-s)-\frac{h T}{2}\right]\left[\phi^{\lambda}\left(p_{i}, r_{i}, E_{i}\right)\right]^{(1 / 1-a)-2}\right\},
\end{aligned}
$$

noting that $\phi^{\lambda}\left(p_{i}, r_{i}, E_{i}\right)^{(1 / 1-a)}-E_{i}>0$ and $\left(\partial L_{2}\left(p_{i}, r_{i}\right) / \quad\right.$ Moreover, $\left.\partial p_{i}\right)<0$, we thus, obtain $\left(\partial \Pi(\mathrm{P}, \mathrm{E}) / \partial p_{i}^{2}\right)<0$.

$$
\begin{aligned}
\frac{\partial \Pi(\mathrm{P}, \mathrm{E})}{\partial E_{i}^{2}}= & z^{i-1} a E^{-a-1}\left[\lambda_{1} A\left(p_{i}, r_{i}\right)+\lambda_{2} B\left(p_{i}, r_{i}\right)-(c-s)-\frac{h T}{2}\right]\left[\phi^{\lambda}\left(p_{i}, r_{i}, E_{i}\right)\right]^{(1 / 1-a)-2} \\
& \times\left[E^{1-a}-\phi^{\lambda}\left(p_{i}, r_{i}, E_{i}\right)\right]<0 .
\end{aligned}
$$

Hence, Proposition 1 can be obtained.

Proof of Lemma 4.

$$
\begin{aligned}
\phi^{\lambda}\left(p_{i}, r_{i}, E_{i}\right) & =E_{i}^{1-a}+(1-a) T\left[\beta_{0}-\beta_{1} p_{i}-\lambda\left(p_{i}-r_{i}\right)\right] \\
& >(1-a) T\left[\beta_{0}-\beta_{1} \bar{p}-\lambda(\bar{p}-\underline{p})\right] \\
& >a\left(\beta_{1}+\lambda\right) T \frac{\lambda_{1} A\left(\bar{p}, r_{i}\right)+\lambda_{2} B\left(\bar{p}, r_{i}\right)-(c-s)-(h T / 2)}{L_{2}\left(\bar{p}, t r_{i}\right)} \\
& >a\left(\beta_{1}+\lambda\right) T \frac{\lambda_{1} A\left(p_{i}, r_{i}\right)+\lambda_{2} B\left(p_{i}, r_{i}\right)-(c-s)-(h T / 2)}{L_{2}\left(p_{i}, r_{i}\right)},
\end{aligned}
$$

where the last inequality follows from the fact that $\left(\lambda_{1} A\left(p_{i}, r_{i}\right)+\lambda_{2} B\left(p_{i}, r_{i}\right)-(c-s)-(h T / 2) / L_{2}\left(p_{i}, r_{i}\right)\right)$ is increasing in $p_{i}$. Moreover, since $\left(\left[\lambda_{1}\left(p_{i}-s\right) g\left(p_{i}-m-\lambda\left(r_{i}-p_{i}\right)\right)+\lambda_{2}\left(p_{i}-s\right) g\left(p_{i}-\right.\right.\right.$ $\left.\left.\lambda\left(r_{i}-p_{i}\right)\right)\right]+a T\left[\lambda_{1} A\left(p_{i}, r_{i}\right)+\lambda_{2} B\left(p_{i}, r_{i}\right)-(c-s)-\right.$ $\left.(h T / 2)] / L_{2}\left(p_{i}, r_{i}\right)\right)$ is also increasing in $p_{i}$, the second inequality is similar to provable.

Proof of Proposition 2.

$$
\begin{aligned}
\frac{\partial^{2} \Pi(\mathrm{P}, \mathrm{E})}{\partial p_{i} \partial r_{1}}= & z^{i-1}\left\{\frac{\partial L_{2}\left(p_{i}, r_{i}\right)}{\partial r_{i}} \alpha^{i-1}\left[\phi^{\lambda}\left(p_{i}, r_{i}, E_{i}\right)\right]^{(1-a / 1)}+\lambda \alpha^{i-1} T L_{2}\left(p_{i}, r_{i}\right)\left[\phi^{\lambda}\left(p_{i}, r_{i}, E_{i}\right)\right]^{(1 / 1-a)-1}\right\} \\
& -z^{i-1}\left\{\left[\lambda_{1}\left(p_{i}-s\right) g\left(p_{i}-m-\lambda\left(r_{i}-p_{i}\right)\right)+\lambda_{2}\left(p_{i}-s\right) g\left(p_{i}-\lambda\left(r_{i}-p_{i}\right)\right)\right]\right. \\
& \times \lambda \alpha^{i-1}\left(\beta_{1}+\lambda\right) T\left[\phi^{\lambda}\left(p_{i}, r_{i}, E_{i}\right)\right]^{(1 / 1-a)-1}-\left[\lambda_{1} A\left(p_{i}, r_{i}\right)+\lambda_{2} B\left(p_{i}, r_{i}\right)-(c-s)-\frac{h T}{2}\right]
\end{aligned}
$$




$$
\begin{aligned}
& \left.\times a \lambda \alpha^{i-1}\left(\beta_{1}+\lambda\right) T^{2}\left[\phi^{\lambda}\left(p_{i}, r_{i}, E_{i}\right)\right]^{(1 / 1-a)-2}-\frac{\partial L_{2}\left(p_{i}, r_{i}\right)}{\partial r_{i}} \alpha^{i-1} E_{i}\right\} \\
& +\sum_{n=i+1}^{\infty} z^{n-1} \lambda^{2}(1-\alpha) \alpha^{2 n-2-i} T^{2}\left[\lambda_{1} A\left(p_{n}, r_{n}\right)+\lambda_{2} B\left(p_{n}, r_{n}\right)-(c-s)-\frac{h T}{2}\right] \\
& \times\left[\phi^{\lambda}\left(p_{i}, r_{i}, E_{i}\right)\right]^{(1 / 1-a)-2}+\sum_{n=i+1}^{\infty} z^{n-1} \lambda(1-\alpha) \alpha^{2 n-2-i} T\left[\phi^{\lambda}\left(p_{i}, r_{i}, E_{i}\right)\right]^{(1 / 1-a)-1} \\
& \times\left[\lambda_{1}\left(p_{n}-s\right) g\left(p_{n}-m-\lambda\left(r_{n}-p_{n}\right)\right)+\lambda_{2}\left(p_{n}-s\right) g\left(p_{n}-\lambda\left(r_{n}-p_{n}\right)\right)\right] \\
& =z^{i-1} \alpha^{i-1} \frac{\partial L_{2}\left(p_{i}, r_{i}\right)}{\partial r_{i}}\left\{\left[\phi^{\lambda}\left(p_{i}, r_{i}, E_{i}\right)\right]^{(1 / 1-a)}-E_{i}\right\}+z^{i-1} \lambda \alpha^{i-1} T\left[\phi^{\lambda}\left(p_{i}, r_{i}, E_{i}\right)\right]^{(1 / 1-a)-2} \\
& \times\left\{L_{2}\left(p_{i}, r_{i}\right) \phi^{\lambda}\left(p_{i}, r_{i}, E_{i}\right)-\left(\beta_{1}+\lambda\right)\right. \\
& {\left[\lambda_{1}\left(p_{i}-s\right) g\left(p_{i}-m-\lambda\left(r_{i}-p_{i}\right)\right)+\lambda_{2}\left(p_{i}-s\right) g\left(p_{i}-\lambda\left(r_{i}-p_{i}\right)\right)\right]} \\
& -a\left(\beta_{1}+\lambda\right) T\left[\lambda_{1} A\left(p_{n}, r_{n}\right)+\lambda_{2} B\left(p_{n}, r_{n}\right)-(c-s)-\frac{h T}{2}\right] \\
& +\sum_{n=i+1}^{\infty} z^{n-1} \lambda^{2}(1-\alpha) \alpha^{2 n-2-i} T^{2}\left[\lambda_{1} A\left(p_{n}, r_{n}\right)+\lambda_{2} B\left(p_{n}, r_{n}\right)-(c-s)-\frac{h T}{2}\right]\left[\phi^{\lambda}\left(p_{i}, r_{i}, E_{i}\right)\right]^{(1 / 1-a)-2} \\
& +\sum_{n=i+1}^{\infty} z^{n-1} \lambda(1-\alpha) \alpha^{2 n-2-i} T\left[\lambda_{1}\left(p_{n}-s\right) g\left(p_{n}-m-\lambda\left(r_{n}-p_{n}\right)\right)+\lambda_{2}\left(p_{n}-s\right) \times g\left(p_{n}-\lambda\left(r_{n}-p_{n}\right)\right)\right]\left[\phi^{\lambda}\left(p_{i}, r_{i}, E_{i}\right)\right]^{(1 / 1-a)-1}
\end{aligned}
$$

$>0$,

$$
\begin{aligned}
& \frac{\partial \Pi(\mathrm{P}, \mathrm{E})}{\partial E_{i} \partial r_{1}}=z^{i-1} \lambda \alpha^{i-1}\left[\lambda_{1}\left(p_{i}-s\right) g\left(p_{i}-m-\lambda\left(r_{i}-p_{i}\right)\right)+\lambda_{2}\left(p_{i}-s\right) g\left(p_{i}-\lambda\left(r_{i}-p_{i}\right)\right)\right] \\
& \times\left\{E_{i}^{-a}\left[\varphi^{\lambda}\left(p_{i}, r_{i}, E_{i}\right)\right]^{(1 / 1-a)-1}-1\right\} \\
& +z^{i-1} a \lambda \alpha^{i-1} T E_{i}^{-a}\left[\lambda_{1} A\left(p_{i}, r_{i}\right)+\lambda_{2} B\left(p_{i}, r_{i}\right)-(c-s)-\frac{h T}{2}\right]\left[\varphi^{\lambda}\left(p_{i}, r_{i}, E_{i}\right)\right]^{(1 / 1-a)-2}>0, \\
& \frac{\partial \Pi(\mathrm{P}, \mathrm{E})}{\partial p_{i} \partial p_{j}}=\frac{\partial}{\partial p_{j}}\left\{\begin{array}{c}
\sum_{n=i+1}^{\infty} z^{n-1} \lambda(1-\alpha) \alpha^{n-1-i} T\left[\lambda_{1} A\left(p_{n}, r_{n}\right)+\lambda_{2} B\left(p_{n}, r_{n}\right)-(c-s)-\frac{h T}{2}\right] \\
\times\left[\phi^{\lambda}\left(p_{n}, r_{n}, E_{n}\right)\right]^{(1 / 1-a)-1}
\end{array}\right\}, \\
& =z^{j-1} \lambda(1-\alpha) \alpha^{j-1-i} T L_{2}\left(p_{j}, r_{j}\right)\left[\phi^{\lambda}\left(p_{i}, r_{i}, E_{i}\right)\right]^{(1 / 1-a)-1}-z^{j-1} a \lambda(1-\alpha) \alpha^{j-1-i}\left(\beta_{1}+\lambda\right) \\
& \times T^{2}\left[\lambda_{1} A\left(p_{j}, r_{j}\right)+\lambda_{2} B\left(p_{j}, r_{j}\right)-(c-s)-\frac{h T}{2}\right]\left[\phi^{\lambda}\left(p_{j}, r_{j}, E_{j}\right)\right]^{(1 / 1-a)-2} \\
& +\sum_{n=j+1}^{\infty} z^{n-1} a \lambda^{2}(1-\alpha)^{2} \alpha^{2 n-i-j-2} T^{2}\left[\lambda_{1} A\left(p_{n}, r_{n}\right)+\lambda_{2} B\left(p_{n}, r_{n}\right)-(c-s)-\frac{h T}{2}\right] \\
& \times\left[\phi^{\lambda}\left(p_{n}, r_{n}, E_{n}\right)\right]^{(1 / 1-a)-2}+\sum_{n=j+1}^{\infty} z^{n-1} \lambda(1-\alpha)^{2} \alpha^{2 n-i-j-2} T L_{2}\left(p_{n}, r_{n}\right)\left[\phi^{\lambda}\left(p_{n}, r_{n}, E_{n}\right)\right]^{(1 / 1-a)-1} \\
& =z^{j-1} \lambda(1-\alpha) \alpha^{j-1-i} T
\end{aligned}
$$




$$
\begin{aligned}
& \left\{L_{2}\left(p_{j}, r_{j}\right)\left[\phi^{\lambda}\left(p_{i}, r_{i}, E_{i}\right)\right]-a\left(\beta_{1}+\lambda\right) T \times\left[\lambda_{1} A\left(p_{j}, r_{j}\right)+\lambda_{2} B\left(p_{j}, r_{j}\right)-(c-s)-\frac{h T}{2}\right]\left[\phi^{\lambda}\left(p_{i}, r_{i}, E_{i}\right)\right]^{(1 / 1-a)-2}\right\} \\
& +\sum_{n=j+1}^{\infty} z^{n-1} a \lambda^{2}(1-\alpha)^{2} \alpha^{2 n-i-j-2} T^{2}\left[\lambda_{1} A\left(p_{n}, r_{n}\right)+\lambda_{2} B\left(p_{n}, r_{n}\right)-(c-s)-\frac{h T}{2}\right] \\
& \times\left[\phi^{\lambda}\left(p_{n}, r_{n}, E_{n}\right)\right]^{(1 / 1-a)-2}+\sum_{n=j+1}^{\infty} z^{n-1} \lambda(1-\alpha)^{2} \alpha^{2 n-i-j-2} T L_{2}\left(p_{n}, r_{n}\right)\left[\phi^{\lambda}\left(p_{n}, r_{n}, E_{n}\right)\right]^{(1 / 1-a)-1} \\
& > \\
\frac{\partial \Pi(\mathrm{P}, \mathrm{E})}{\partial p_{i} \partial E_{j}} & = \begin{cases}0, & i>j, \\
-z^{i-1} L_{2}\left(p_{i}, r_{i}\right)+z^{i-1} L_{2}\left(p_{i}, r_{i}\right)\left[\phi^{\lambda}\left(p_{i}, r_{i}, E_{i}\right)\right]^{(1 / 1-a)-1} E_{i}^{-a}-z^{i-1} a\left(\beta_{1}+\lambda\right) & i=j, \\
\times T\left[\lambda_{1} A\left(p_{i}, r_{i}\right)+\lambda_{2} B\left(p_{i}, r_{i}\right)-(c-s)-\frac{h T}{2}\right]\left[\phi^{\lambda}\left(p_{i}, r_{i}, E_{i}\right)\right]^{(1 / 1-a)-2} E_{i}^{-a}, & \\
z^{j-1} a \lambda(1-\alpha) \alpha^{j-1-i} T\left[\lambda_{1} A\left(p_{j}, r_{j}\right)+\lambda_{2} B\left(p_{j}, r_{j}\right)-(c-s)-\frac{h T}{2}\right] & i<j, \\
\times\left[\phi^{\lambda}\left(p_{j}, r_{j}, E_{j}\right)\right]^{(1 / 1-a)-2} E_{j}^{-a} . & \end{cases}
\end{aligned}
$$

and $\left(\partial \Pi(\mathrm{P}, \mathrm{E}) / \partial E_{i} E_{j}\right)=0$, respectively. Because

$$
\begin{aligned}
& -z^{i-1} L_{2}\left(p_{i}, r_{i}\right)+z^{i-1} L_{2}\left(p_{i}, r_{i}\right)\left[\phi^{\lambda}\left(p_{i}, r_{i}, E_{i}\right)\right]^{(1 / 1-a)-1} E_{i}^{-a}-z^{i-1} a\left(\beta_{1}+\lambda\right) T \\
& \quad \times\left[\lambda_{1} A\left(p_{i}, r_{i}\right)+\lambda_{2} B\left(p_{i}, r_{i}\right)-(c-s)-\frac{h T}{2}\right]\left[\phi^{\lambda}\left(p_{i}, r_{i}, E_{i}\right)\right]^{(1 / 1-a)-2} E_{i}^{-a} \\
& \quad \geq-z^{i-1} L_{2}\left(p_{i}, r_{i}\right)+z^{i-1} L_{2}\left(p_{i}, r_{i}\right)\left[\phi^{\lambda}\left(p_{i}, r_{i}, E_{i}\right)\right]^{(1 / 1-a)-2} \\
& E_{i}^{-a}\left\{\phi^{\lambda}\left(p_{i}, r_{i}, E_{i}\right)-a\left(\beta_{1}+\lambda\right) T\left[\lambda_{1} A\left(p_{i}, r_{i}\right)+\lambda_{2} B\left(p_{i}, r_{i}\right)-(c-s)-\frac{h T}{2}\right]\right\} \\
& \quad \geq-z^{i-1} L_{2}\left(p_{i}, r_{i}\right)+z^{i-1} L_{2}\left(p_{i}, r_{i}\right) E_{i}^{-1+2 a} E_{i}^{1-2 a} \\
& \quad=0,
\end{aligned}
$$

$\left(\partial \Pi(\mathrm{P}, \mathrm{E}) / \partial p_{i} E_{j}\right) \geq 0$. In summary, $\Pi(\mathrm{P}, \mathrm{E})$ is supermodular in $\left(\mathrm{P}, \mathrm{E}, r_{1}\right)$. Hence, $\left\{p_{i}^{*}\right\}_{i=1}^{\infty}$ and $\left\{E_{i}^{*}\right\}_{i=1}^{\infty}$ are both increasing in $r_{1}$.

\section{Proof of Proposition 3.}

(i) Problem (10) can be rewritten in the following form:

$$
\begin{aligned}
\max _{(\mathrm{P}, \mathrm{E}) \in \Omega} \Pi(\mathrm{P}, \mathrm{E})= & \pi\left(p_{1}^{*}, r_{1}^{*}, E_{1}^{*}\right) \\
& +z \max _{(\mathrm{P}, \mathrm{E}) \in \Omega} \sum_{i=2}^{\infty} z^{i-2} \pi\left(p_{i}, r_{i}, E_{i}\right) .
\end{aligned}
$$

If $p_{1}^{*}>r_{1}$, then $r_{2}^{*}=\alpha r_{1}^{*}+(1-\alpha) p_{1}^{*}\left(r_{1}^{*}\right)>r_{1}^{*}$. It follows from the supermodularity of $\Pi(\mathrm{P}, \mathrm{E})$ in $\left(\mathrm{P}, \mathrm{E}, r_{1}\right)$ that there are $p_{2}^{*}\left(r_{2}^{*}\right) \geq p_{2}^{*}\left(r_{1}^{*}\right)=p_{1}^{*}\left(r_{1}^{*}\right)$ and $E_{2}^{*}\left(r_{2}^{*}\right) \geq E_{2}^{*}\left(r_{1}^{*}\right)=$ $E_{1}^{*}\left(r_{1}^{*}\right)$. Similarly, we have $p_{3}^{*}\left(r_{3}^{*}\right) \geq p_{2}^{*}\left(r_{2}^{*}\right)=p_{2}^{*}\left(r_{2}^{*}\right)$ and $E_{3}^{*}\left(r_{3}^{*}\right) \geq E_{3}^{*}\left(r_{2}^{*}\right)=E_{2}^{*}\left(r_{2}^{*}\right) \quad$ according to $r_{3}^{*}=\alpha r_{2}^{*}+$ $(1-\alpha) p_{2}^{*}\left(r_{2}^{*}\right)$. By induction, we can obtain that $p_{1}^{*} \leq p_{2}^{*} \leq$ $p_{3}^{*} \leq \cdots \leq p_{\infty}^{*}$ and $E_{1}^{*} \leq E_{2}^{*} \leq E_{3}^{*} \leq \cdots \leq E_{\infty}^{*}$. Similarly, we can get (ii) and (iii).

Proof of Proposition 4. Suppose the selling price reaches the equilibrium $p_{e}$ in the nth period; we have $p_{e}-r_{i}=p_{e}-$ $\alpha^{i-n} r_{n}-(1-\alpha) p_{e} \sum_{j=0}^{i-n} \alpha^{i-n-j}=\alpha^{i-n}\left(p_{e}-r_{n}\right)$ for all $i \geq n$, which implies that the reference price converges to $p_{e}$ as $i \longrightarrow \infty$. Thus, the discounted total profit from period $n$ to infinite can be rewritten as 


$$
\begin{aligned}
\sum_{i=n}^{\infty} z^{i-1} \pi\left(p_{e}, r_{i}, E_{i}\right)= & \sum_{i=n}^{\infty} z^{i-1}\left[\lambda_{1} A\left(p_{e}, r_{n}\right)+\lambda_{2} B\left(p_{e}, r_{n}\right)-(c-s)-\frac{h T}{2}\right] \\
& \times\left\{(1-a) T\left[\beta_{0}-\beta_{1} p_{e}-\lambda \alpha^{i-n}\left(p_{e}-r_{n}\right)\right]+E_{i}^{1-a}\right\}^{(1 / 1-a)} \\
& -\sum_{i=n}^{\infty} z^{i-1} E_{i}\left[\lambda_{1} A\left(p_{e}, r_{n}\right)+\lambda_{2} B\left(p_{e}, r_{n}\right)+\frac{h T}{2}\right]
\end{aligned}
$$

The problem is simplified to derive $p_{e}$ and $\left\{E_{i}\right\}_{i=n}^{\infty}$ in order to maximize $\Pi\left(\mathrm{P}_{e}, \mathrm{E}\right)$. The first-order conditions for an interior maximum are as follows:

$$
\begin{aligned}
\frac{\partial \sum_{i=n}^{\infty} z^{i-1} \pi\left(p_{e}, r_{i}, E_{i}\right)}{\partial p_{e}}= & \sum_{i=n}^{\infty} z^{i-1} L_{2}\left(p_{e}, r_{n}\right)\left[(1-a) T\left[\beta_{0}-\beta_{1} p_{e}-\lambda \alpha^{i-n}\left(p_{e}-r_{n}\right)\right]+E_{i}^{1-a}\right]^{(1 / 1-a)} \\
& -\sum_{i=n}^{\infty} z^{i-1}\left(\beta_{1}+\lambda \alpha^{i-n}\right) T\left[\lambda_{1} A\left(p_{e}, r_{n}\right)+\lambda_{2} B\left(p_{e}, r_{n}\right)-(c-s)-\frac{h T}{2}\right] \\
& \times\left\{(1-a) T\left[\beta_{0}-\beta_{1} p_{e}-\lambda \alpha^{i-n}\left(p_{e}-r_{n}\right)\right]+E_{i}^{1-a}\right\}^{(1 / 1-a)-1} \\
& -\sum_{i=n}^{\infty} z^{i-1} L_{2}\left(p_{e}, r_{n}\right) E_{i}=0, \\
\frac{\partial \sum_{i=n}^{\infty} z^{i-1} \pi\left(p_{e}, r_{i}, E_{i}\right)}{\partial E_{i}}= & \sum_{i=n}^{\infty} z^{i-1} E_{i}^{-a}\left[\lambda_{1} A\left(p_{e}, r_{n}\right)+\lambda_{2} B\left(p_{e}, r_{n}\right)-(c-s)-\frac{h T}{2}\right]\left\{(1-a) T\left[\beta_{0}-\beta_{1} p_{e}-\lambda \alpha^{i-n}\left(p_{e}-r_{n}\right)\right]+E_{i}^{1-a}\right\} \\
& -\sum_{i=n}^{\infty} z^{i-1}\left[\lambda_{1} A\left(p_{e}, r_{n}\right)+\lambda_{2} B\left(p_{e}, r_{n}\right)+\frac{h T}{2}\right]=0, \quad i=n, n+1, n+2, \ldots,
\end{aligned}
$$

respectively. Since $\lim _{n \rightarrow \infty}\left(p_{e}-r_{n}\right)=0$, we have $r_{n}=p_{e}$ if $n$ is sufficiently large. Thus, substituting $p_{e}=r_{n}$ into the first-order conditions, we get

$$
\begin{aligned}
\frac{\partial \sum_{i=n}^{\infty} z^{i-1} \pi\left(p_{e}, r_{i}, E_{i}\right)}{\partial p_{e}}= & \sum_{i=n}^{\infty} z^{i-1} L_{2}\left(p_{e}, p_{e}\right)\left[(1-a)\left(\beta_{0}-\beta_{1} p_{e}\right) T+E_{i}^{1-a}\right]^{(1 / 1-a)} \\
& -\sum_{i=n}^{\infty} z^{i-1}\left(\beta_{1}+\lambda \alpha^{i-n}\right) T\left[\lambda_{1} A\left(p_{e}, p_{e}\right)+\lambda_{2} B\left(p_{e}, p_{e}\right)-(c-s)-\frac{h T}{2}\right] \\
& \times\left\{(1-a)\left(\beta_{0}-\beta_{1} p_{e}\right) T+E_{i}^{1-a}\right\}^{(1 / 1-a)-1}-\sum_{i=n}^{\infty} z^{i-1} L_{2}\left(p_{e}, p_{e}\right) E_{i}=0 \\
0= & \sum_{i=n}^{\infty} z^{i-1} E_{i}^{-a}\left[\lambda_{1} A\left(p_{e}, p_{e}\right)+\lambda_{2} B\left(p_{e}, p_{e}\right)-(c-s)-\frac{h T}{2}\right]\left\{(1-a)\left(\beta_{0}-\beta_{1} p_{e}\right) T+E_{i}^{1-a}\right\} \\
& -\sum_{i=n}^{\infty} z^{i-1}\left[\lambda_{1} A\left(p_{e}, p_{e}\right)+\lambda_{2} B\left(p_{e}, p_{e}\right)+\frac{h T}{2}\right]
\end{aligned}
$$


From the last equation, we can see that $E_{e}=E_{n}=E_{n+1}=E_{n+2}=\cdots$. Substituting this result into previous equations and after rearranging terms, we get

$$
\begin{aligned}
L_{2}\left(p_{e}, p_{e}\right)\left[\phi^{\lambda}\left(p_{e}, p_{e}, E_{e}\right)\right]^{(1 / 1-a)}= & \left(\beta_{1}+\lambda \frac{1-z}{1-\alpha z}\right) T\left[\lambda_{1} A\left(p_{e}, p_{e}\right)+\lambda_{2} B\left(p_{e}, p_{e}\right)-(c-s)-\frac{h T}{2}\right] \\
& \times\left[\phi^{\lambda}\left(p_{e}, p_{e}, E_{e}\right)\right]^{(1 / 1-a)-1}+E_{e}, \\
{\left[\lambda_{1} A\left(p_{e}, p_{e}\right)+\lambda_{2} B\left(p_{e}, p_{e}\right)+\frac{h T}{2}\right] E_{e}^{a}=} & {\left[\lambda_{1} A\left(p_{e}, p_{e}\right)+\lambda_{2} B\left(p_{e}, p_{e}\right)-(c-s)-\frac{h T}{2}\right] } \\
& \times\left[\phi^{\lambda}\left(p_{e}, p_{e}, E_{e}\right)\right]^{(1 / 1-a)-1},
\end{aligned}
$$

or equivalently,

$$
\left(\frac{\lambda_{1} A\left(p_{e}, p_{e}\right)+\lambda_{2} B\left(p_{e}, p_{e}\right)+(h T / 2)}{\lambda_{1} A\left(p_{e}, p_{e}\right)+\lambda_{2} B\left(p_{e}, p_{e}\right)-(c-s)-(h T / 2)}\right)^{(1-a / a)}=1+\frac{(1-a)\left(\beta_{0}-\beta_{1} p_{e}\right) T}{E_{e}^{1-a}}
$$

After some algebraic manipulations, we get

$$
\begin{aligned}
& L_{2}\left(p_{e}, p_{e}\right)\left(\frac{\lambda_{1} A\left(p_{e}, p_{e}\right)+\lambda_{2} B\left(p_{e}, p_{e}\right)+(h T / 2)}{\lambda_{1} A\left(p_{e}, p_{e}\right)+\lambda_{2} B\left(p_{e}, p_{e}\right)-(c-s)-(h T / 2)}\right)^{(1 / a)}-1 \\
&=\frac{\left(\beta_{1}+\lambda(1-z / 1-\alpha z)\right)\left[\lambda_{1} A\left(p_{e}, p_{e}\right)+\lambda_{2} B\left(p_{e}, p_{e}\right)-(c-s)-(h T / 2)\right]}{(1-a)\left(\beta_{0}-\beta_{1} p_{e}\right)} \\
& \times\left[\left(\frac{\lambda_{1} A\left(p_{e}, p_{e}\right)+\lambda_{2} B\left(p_{e}, p_{e}\right)+(h T / 2)}{\lambda_{1} A\left(p_{e}, p_{e}\right)+\lambda_{2} B\left(p_{e}, p_{e}\right)-(c-s)-(h T / 2)}\right)^{(1 / a)}-\left(\frac{\lambda_{1} A\left(p_{e}, p_{e}\right)+\lambda_{2} B\left(p_{e}, p_{e}\right)+(h T / 2)}{\lambda_{1} A\left(p_{e}, p_{e}\right)+\lambda_{2} B\left(p_{e}, p_{e}\right)-(c-s)-(h T / 2)}\right)\right], \\
& E_{e}= {\left[\frac{(1-a) T\left(\beta_{0}-\beta_{1} p_{e}\right)}{\left(\lambda_{1} A\left(p_{e}, p_{e}\right)+\lambda_{2} B\left(p_{e}, p_{e}\right)+(h T / 2) / \lambda_{1} A\left(p_{e}, p_{e}\right)+\lambda_{2} B\left(p_{e}, p_{e}\right)-(c-s)-(h T / 2)\right)^{(1-a / a)}-1}\right] }
\end{aligned}
$$


This completes the proof.

Proof of Proposition 5 (i) Taking the cross-partial derivatives of $\sum_{i=n}^{\infty} z^{i-1} \pi\left(p_{e}, r_{i}, E_{i}\right)$ with respect to $p_{e}, E_{i}$, and $\lambda$ yields

$$
\begin{aligned}
\frac{\partial^{2} \sum_{i=n}^{\infty} z^{i-1} \pi\left(p_{e}, r_{i}, E_{i}\right)}{\partial p_{e} \partial \lambda}= & -\sum_{i=n}^{\infty} z^{i-1} \alpha^{i-n}\left(p_{e}-r_{n}\right) T L_{2}\left(p_{e}, r_{n}\right)\left[\phi^{\lambda}\left(p_{e}, r_{n}, E_{i}\right)\right]^{(1 / 1-a)} \\
& -\sum_{i=n}^{\infty} z^{i-1} \alpha^{i-n} T\left[\lambda_{1} A\left(p_{e}, r_{n}\right)+\lambda_{2} B\left(p_{e}, r_{n}\right)-(c-s)-\frac{h T}{2}\right] \\
& \times\left[\phi^{\lambda}\left(p_{e}, r_{n}, E_{i}\right)\right]^{(1 / 1-a)-1}+\sum_{i=n}^{\infty} z^{i-1} a \alpha^{i-n}\left(p_{e}-r_{n}\right)\left(\beta_{1}+\lambda \alpha^{i-n}\right) T^{2} \\
& \times\left[\lambda_{1} A\left(p_{e}, r_{n}\right)+\lambda_{2} B\left(p_{e}, r_{n}\right)-(c-s)-\frac{h T}{2}\right]\left[\phi^{\lambda}\left(p_{e}, r_{n}, E_{i}\right)\right]^{(1 / 1-a)-2}, \\
\frac{\partial^{2} \sum_{i=n}^{\infty} z^{i-1} \pi\left(p_{e}, r_{i}, E_{i}\right)}{\partial E_{i} \partial \lambda}= & -\sum_{i=n}^{\infty} z^{i-1} a \alpha^{i-n}\left(p_{e}-r_{n}\right) T E_{i}^{-a}\left[\phi^{\lambda}\left(p_{e}, r_{n}, E_{i}\right)\right] \\
& \times\left[\lambda_{1} A\left(p_{e}, r_{n}\right)+\lambda_{2} B\left(p_{e}, r_{n}\right)-(c-s)-\frac{h T}{2}\right]<0, \\
\frac{\partial^{2} \sum_{i=n}^{\infty} z^{i-1} \pi\left(p_{e}, r_{i}, E_{i}\right)}{\partial p_{e} \partial E_{i}}= & \sum_{i=n}^{\infty} z^{i-1} E_{i}^{-a} L_{2}\left(p_{e}, r_{n}\right)\left[\phi^{\lambda}\left(p_{e}, r_{n}, E_{i}\right)\right]^{(1 / 1-a)-1}-\sum_{i=n}^{\infty} z^{i-1} L_{2}\left(p_{e}, r_{n}\right) \\
& -\sum_{i=n}^{\infty} z^{i-1} a E_{i}^{-a}\left(\beta_{1}+\lambda \alpha^{i-n}\right) T\left[\phi^{\lambda}\left(p_{e}, r_{n}, E_{i}\right)\right] \\
& \times\left[\lambda_{1} A\left(p_{e}, r_{n}\right)+\lambda_{2} B\left(p_{e}, r_{n}\right)-(c-s)-\frac{h T}{2}\right] \\
\geq & z^{i-1} L_{2}\left(p_{e}, r_{n}\right)+z^{i-1} L_{2}\left(p_{e}, r_{n}\right) E_{i}^{-1+2 a} E_{i}^{1-2 a} \\
= & 0 .
\end{aligned}
$$

Since $r_{n}=p_{e}$ when $n$ is sufficiently large,

$$
\begin{aligned}
\frac{\partial^{2} \sum_{i=n}^{\infty} z^{i-1} \pi\left(p_{e}, r_{i}, E_{i}\right)}{\partial p_{e} \partial \lambda}= & -\sum_{i=n}^{\infty} z^{i-1} \alpha^{i-n} T\left[\lambda_{1} A\left(p_{e}, r_{n}\right)+\lambda_{2} B\left(p_{e}, r_{n}\right)-(c-s)-\frac{h T}{2}\right] \\
& \times\left[\phi^{\lambda}\left(p_{e}, r_{n}, E_{i}\right)\right]^{(1 / 1-a)-1}<0 .
\end{aligned}
$$

In summary, $\sum_{i=n}^{\infty} z^{i-1} \pi\left(p_{e}, r_{i}, E_{i}\right)$ is supermodular in $\left(-p_{e},-E_{i}, \lambda\right)$, which implies the equilibrium (ii) Let selling price $p_{e}$ and ending inventory level $E_{e}$ both decrease with $\lambda$.

$$
\begin{aligned}
\psi\left(p_{e}, E_{e}\right)= & L_{2}\left(p_{e}, p_{e}\right)\left[\varphi^{\lambda}\left(p_{e}, p_{e}, E_{e}\right)\right]^{(1 / 1-a)}-\left(\beta_{1}+\lambda \frac{1-z}{1-\alpha z}\right) T \\
& \cdot\left[\lambda_{1} A\left(p_{e}, p_{e}\right)+\lambda_{2} B\left(p_{e}, p_{e}\right)-(c-s)-\frac{h T}{2}\right]\left[\varphi^{\lambda}\left(p_{e}, p_{e}, E_{e}\right)\right]^{(1 / 1-a)-1}+E_{e} .
\end{aligned}
$$


From the implicit function theorem, we have

$$
\begin{aligned}
\frac{d p_{e}}{\mathrm{~d} \alpha} & =-\frac{\left(\partial \psi\left(p_{e}, E_{e}\right) / \partial \alpha\right)}{\left(\partial \psi\left(p_{e}, E_{e}\right) / \partial p_{e}\right)}, \\
& =\frac{-\left((1-z) z /(1-\alpha z)^{2}\right) T\left[\lambda_{1} A\left(p_{e}, p_{e}\right)+\lambda_{2} B\left(p_{e}, p_{e}\right)-(c-s)-(h T / 2)\right]\left[\phi^{\lambda}\left(p_{e}, p_{e}, E_{e}\right)\right]^{(1 / 1-a)-1}}{-\left(\partial \psi\left(p_{e}, E_{e}\right) / \partial p_{e}\right)},
\end{aligned}
$$

it follows from Proposition 2 that $-\left(\partial \psi\left(p_{e}, E_{e}\right) / \partial p_{e}\right)>0$; then, we have $\left(d p_{e} / \mathrm{d} \alpha\right)<0$. Therefore, $p_{e}$ is decreasing in $\alpha$.

Moreover, because $\sum_{i=n}^{\infty} z^{i-1} \pi\left(p_{e}, r_{i}, E_{i}\right)$ is supermodular in $\left(p_{e}, E_{e}\right)$, we have

$$
\frac{d E_{e}}{\mathrm{~d} \alpha}=\frac{\partial E_{e}}{\partial \alpha}+\frac{\partial E_{e}}{\partial p_{e}} \frac{d p_{e}}{\mathrm{~d} \alpha}=\frac{\partial E_{e}}{\partial p_{e}} \frac{d p_{e}}{\mathrm{~d} \alpha}<0 .
$$

Hence, $E_{e}$ is decreasing in $\alpha$. (iii) From the implicit function theorem, we get

$$
\begin{aligned}
\frac{d p_{e}}{\mathrm{~d} m} & =-\frac{\left(\partial^{2} \sum_{i=n}^{\infty} z^{i-1} \pi\left(p_{e}, r_{i}, E_{i}\right) / \partial p_{e} \partial m\right)}{\left(\partial^{2} \sum_{i=n}^{\infty} z^{i-1} \pi\left(p_{e}, r_{i}, E_{i}\right) / \partial p_{e}^{2}\right)} \\
& =\frac{\left(\partial^{2} \sum_{i=n}^{\infty} z^{i-1} \pi\left(p_{e}, r_{i}, E_{i}\right) / \partial p_{e} \partial m\right)}{-\left(\partial^{2} \sum_{i=n}^{\infty} z^{i-1} \pi\left(p_{e}, r_{i}, E_{i}\right) / \partial p_{e}^{2}\right)} .
\end{aligned}
$$

Since

$$
\begin{aligned}
\frac{\partial^{2} \sum_{i=n}^{\infty} z^{i-1} \pi\left(p_{e}, r_{i}, E_{i}\right)}{\partial p_{e} \partial m}= & \sum_{i=n}^{\infty} z^{i-1} \lambda_{1}\left[g\left(p_{e}-m\right)+\left(p_{e}-s\right)(1+\lambda) g^{\prime}\left(p_{e}-m\right)\right] \\
& \times\left\{\left[(1-a)\left(\beta_{0}-\beta_{1} p_{e}\right) T+E_{i}^{1-a}\right]^{(1 / 1-a)}-E_{i}\right\} \\
& >0
\end{aligned}
$$

$\left(d p_{e} / \mathrm{d} m\right)>0$, where $p_{e}$ is increasing in $m$.

$$
\frac{d E_{e}}{\mathrm{~d} m}=-\frac{\left(\partial^{2} \sum_{i=n}^{\infty} z^{i-1} \pi\left(p_{e}, r_{i}, E_{i}\right) / \partial E_{e} \partial m\right)}{\left(\partial^{2} \sum_{i=n}^{\infty} z^{i-1} \pi\left(p_{e}, r_{i}, E_{i}\right) / \partial E_{e}^{2}\right)}=\frac{\left(\partial^{2} \sum_{i=n}^{\infty} z^{i-1} \pi\left(p_{e}, r_{i}, E_{i}\right) / \partial E_{e} \partial m\right)}{-\left(\partial^{2} \sum_{i=n}^{\infty} z^{i-1} \pi\left(p_{e}, r_{i}, E_{i}\right) / \partial E_{e}^{2}\right)} .
$$

Since

$$
\begin{aligned}
\frac{\partial^{2} \sum_{i=n}^{\infty} z^{i-1} \pi\left(p_{e}, r_{i}, E_{i}\right)}{\partial E_{i} \partial m}= & \sum_{i=n}^{\infty} z^{i-1} E_{i}^{-a} \lambda_{1}\left[g\left(p_{e}-m\right)+\left(p_{e}-s\right)(1+\lambda) g^{\prime}\left(p_{e}-m\right)\right] \\
& \times\left\{(1-a)\left(\beta_{0}-\beta_{1} p_{e}\right) T+E_{i}^{1-a}\right\}^{(1 / 1-a)-1} \\
& -\sum_{i=n}^{\infty} z^{i-1} \lambda_{1}\left[g\left(p_{e}-m\right)+\left(p_{e}-s\right)(1+\lambda) g^{\prime}\left(p_{e}-m\right)\right]>0,
\end{aligned}
$$

$\left(d E_{e} / \mathrm{d} m\right)>0$, where $E_{e}$ is increasing in $m$. 
(iv) From the implicit function theorem, we get

$$
\frac{d p_{e}}{\mathrm{~d} l}=-\frac{\left(\partial^{2} \sum_{i=n}^{\infty} z^{i-1} \pi\left(p_{e}, r_{i}, E_{i}\right) / \partial p_{e} \partial l\right)}{\left(\partial^{2} \sum_{i=n}^{\infty} z^{i-1} \pi\left(p_{e}, r_{i}, E_{i}\right) / \partial p_{e}^{2}\right)}=\frac{\left(\partial^{2} \sum_{i=n}^{\infty} z^{i-1} \pi\left(p_{e}, r_{i}, E_{i}\right) / \partial p_{e} \partial l\right)}{-\left(\partial^{2} \sum_{i=n}^{\infty} z^{i-1} \pi\left(p_{e}, r_{i}, E_{i}\right) / \partial p_{e}^{2}\right)}
$$

Since

$$
\frac{\partial^{2} \sum_{i=n}^{\infty} z^{i-1} \pi\left(p_{e}, r_{i}, E_{i}\right)}{\partial p_{e} \partial l}=\sum_{i=n}^{\infty} z^{i-1} \lambda_{2}\left\{\left[(1-a)\left(\beta_{0}-\beta_{1} p_{e}\right) T+E_{i}^{1-a}\right]^{(1 / 1-a)}-E_{i}\right\}>0,
$$

$\left(d p_{e} / \mathrm{d} m\right)>0$, where $p_{e}$ is increasing in $l$.

$$
\frac{d E_{e}}{\mathrm{~d} l}=-\frac{\left(\partial^{2} \sum_{i=n}^{\infty} z^{i-1} \pi\left(p_{e}, r_{i}, E_{i}\right) / \partial E_{e} \partial l\right)}{\left(\partial^{2} \sum_{i=n}^{\infty} z^{i-1} \pi\left(p_{e}, r_{i}, E_{i}\right) / \partial E_{e}^{2}\right)}=\frac{\left(\partial^{2} \sum_{i=n}^{\infty} z^{i-1} \pi\left(p_{e}, r_{i}, E_{i}\right) / \partial E_{e} \partial l\right)}{-\left(\partial^{2} \sum_{i=n}^{\infty} z^{i-1} \pi\left(p_{e}, r_{i}, E_{i}\right) / \partial E_{e}^{2}\right)} .
$$

Since

$$
\frac{\partial^{2} \sum_{i=n}^{\infty} z^{i-1} \pi\left(p_{e}, r_{i}, E_{i}\right)}{\partial E_{i} \partial m}=\sum_{i=n}^{\infty} z^{i-1} \lambda_{2} E_{i}^{-a}\left\{(1-a)\left(\beta_{0}-\beta_{1} p_{e}\right) T+E_{i}^{1-a}\right\}^{(1 / 1-a)-1}-\sum_{i=n}^{\infty} z^{i-1} \lambda_{2}>0,
$$

$\left(d E_{e} / \mathrm{d} m\right)>0$, where $E_{e}$ is increasing in $l$. This completes the proof.

Proof of Proposition 7. It follows from Proposition 1 that $\pi^{\lambda}\left(p_{i}, r_{i}, E_{i}\right)$ is concave in $p_{e}$ and $E_{e}$. Similarly, it can be proved that $\pi^{\gamma}\left(p_{i}, r_{i}, E_{i}\right)$ is concave in $p_{e}$ and $E_{e}$. Since minimization preserves the concavity, this thus, gives the proof.

Proof of Proposition 8. The proof is similar to that of Theorem 7 in [24], which we omit here.

\section{Data Availability}

Data used to support the findings of this study can be obtained from the corresponding author on request.

\section{Conflicts of Interest}

The authors declare that they have no conflicts of interest.

\section{Acknowledgments}

This work was supported by the Nature Science Foundation of Inner Mongolia Autonomous Region (Grant no. 2020MS07008) and the Nature Science Foundation of Hebei Province (Grant no. G2019203387).

\section{References}

[1] D. Rigby, “The future of shopping," Harvard Business Review, vol. 89, no. 12, pp. 64-75, 2011.

[2] S. Saghiri, R. Wilding, C. Mena, and M. Bourlakis, "Toward a three-dimensional framework for omni-channel," Journal of Business Research, vol. 77, pp. 53-67, 2017.

[3] Statista, "B2C e-commerce sales worldwide from 2012-2018," 2019.

[4] H. F. Peng and M. Y. Huang, "Retail business model innovation and its path analysis under the new technology environment-Taking Suning cloud business as an example (in Chinese)," Macroeconomic Research, vol. 2, pp. 108-115, 2014.

[5] J. Zhang, Q. Xu, and Y. He, "Omnichannel retail operations with consumer returns and order cancellation," Transportation Research Part E: Logistics and Transportation Review, vol. 118, no. 4, pp. 308-324, 2018.

[6] UPS, UPS Online Shopping Study: Empowered Consumers Changing the Future of Retail, United Parcel Service of America, Atlanta, GA, USA, 2015.

[7] G. Kalyanaram and R. S. Winer, "Empirical generalizations from reference price research," Marketing Science, vol. 14, no. 3, pp. 161-169, 1995.

[8] X. Chen, P. Hu, S. Shum, and Y. Zhang, "Dynamic stochastic inventory management with reference price effects," Operations Research, vol. 64, no. 6, pp. 1529-1536, 2016.

[9] L. R. Liu and Q. Xu, "Joint decisions on pricing and ordering for omnichannel BOPS retailers: considering online returns," Sustainability, vol. 12, no. 4, pp. 1-18, 2020. 
[10] M. G. Güler, T. Bïlgiç, and R. Güllü, "Joint inventory and pricing decisions with reference effects," IIE Transactions, vol. 46, no. 4, pp. 330-343, 2014.

[11] M. G. Güler, T. Bilgiç, and R. Güllü, "Joint pricing and inventory control for additive demand models with reference effects," Annals of Operations Research, vol. 226, no. 1, pp. 255-276, 2015.

[12] P. Rosenblum and B. Kilcourse, Omni-channel 2013: The Long Road to Adoption, Retail System Research, London, UK, 2013.

[13] F. Gao and X. Su, "Omnichannel retail operations with buyonline-and-pick-up-in-store," Management Science, vol. 63, no. 8, pp. 2478-2492, 2017.

[14] S. Halzack, "From new mobile offerings to a potential off-price business," 2015.

[15] P. Zhang, Y. He, and X. Zhao, “"Preorder-online, pickup-in-store” strategy for a dual-channel retailer," Transportation Research Part E: Logistics and Transportation Review, vol. 122, pp. 27-47, 2019.

[16] P. Harsha, S. Subramanian, and J. Yichanco, "Dynamic pricing of omnichannel inventories," Manufacturing \& Service Operations Management, vol. 21, no. 1, pp. 47-65, 2019.

[17] C. Fan, Y. M. Liu, X. H. Yang, X. H. Chen, and J. H. Hu, "Online and offline cooperation under buy-online, pick-up-in-store: pricing and inventory decisions," Journal of Industrial and Management Optimization, vol. 15, no. 3, pp. 1455-1472, 2019.

[18] M. Jin, G. Li, and T. C. E. Cheng, "Buy online and pick up in-store: design of the service area," European Journal of Operational Research, vol. 268, no. 2, pp. 613-623, 2018.

[19] L. Gimpl-Heersink, C. Rudloff, M. Fleischmann, and A. Taudes, "Integrating pricing and inventory control: is it worth the effort?" Business Research, vol. 1, no. 1, pp. 106-123, 2008.

[20] T. L. Urban, "Coordinating pricing and inventory decisions under reference price effects," International Journal of Manufacturing Technology and Management, vol. 13, no. 1, pp. 78-94, 2008.

[21] A. Taudes and C. Rudloff, "Integrating inventory control and a price change in the presence of reference price effects: a two-period model," Mathematical Methods of Operations Research, vol. 75, no. 1, pp. 1-37, 2012.

[22] Y. Zhang, Essays on Robust Optimization, Integrated Inventory and Pricing, and Reference Price Effect, University of Illinois at Urbana-Champaign, Illinois, IL, USA, 2010.

[23] X. Chen, P. Hu, and S. He, "Technical note-preservation of supermodularity in parametric optimization problems with nonlattice structures," Operations Research, vol. 61, no. 5, pp. 1166-1173, 2013.

[24] R. Li and J.-T. Teng, "Pricing and lot-sizing decisions for perishable goods when demand depends on selling price, reference price, product freshness, and displayed stocks," European Journal of Operational Research, vol. 270, no. 3, pp. 1099-1108, 2018.

[25] H. Ren and T. Huang, "Modeling customer bounded rationality in operations management: a review and research opportunities," Computers \& Operations Research, vol. 91, pp. 48-58, 2018.

[26] T.-M. Choi and S. Guo, "Responsive supply in fashion mass customisation systems with consumer returns," International Journal of Production Research, vol. 56, no. 10, pp. 3409-3422, 2017.

[27] Z. Pei, L. Toombs, and R. Yan, "How does the added new online channel impact the supporting advertising expenditure?" Journal of Retailing and Consumer Services, vol. 21, no. 3, pp. 229-238, 2014.
[28] P. Harsha and S. Subramanian, "U.S. Patent Application No. 15/199," 2018.

[29] C.-Y. Dye, "Optimal joint dynamic pricing, advertising and inventory control model for perishable items with psychic stock effect," European Journal of Operational Research, vol. 283, no. 2, pp. 576-587, 2020.

[30] P. He, Y. He, and H. Xu, "Channel structure and pricing in a dual-channel closed-loop supply chain with government subsidy," International Journal of Production Economics, vol. 213, pp. 108-123, 2019. 